\title{
Dry sliding wear of epoxy/cenosphere syntactic foams
}

Vyasaraj Manakari and Gururaj Parande ${ }^{1}$

${ }^{1}$ Department of Mechanical Engineering, BVB College of Engineering and Technology, Hubli, Karnataka, India

Mrityunjay Doddamani ${ }^{2}$

${ }^{2}$ Lightweight Materials Laboratory, Department of Mechanical Engineering, National Institute of Technology Karnataka, Surathkal, India

V. N. Gaitonde, I. G. Siddhalingeshwar ${ }^{3}$

${ }^{3}$ Department of Industrial Production and Automobile Engineering, BVB College of Engineering and Technology, Hubli, Karnataka, India

\author{
Kishore $^{4}$ \\ ${ }^{4}$ Department of Materials Engineering, Indian Institute of Science, Bangalore, India \\ Vasanth Chakravarthy Shunmugasamy, Nikhil Gupta ${ }^{5, *}$ \\ ${ }^{5}$ Composite Materials and Mechanics Laboratory, Mechanical and Aerospace Engineering \\ Department, Polytechnic School of Engineering, New York University, Brooklyn, NY 11201 \\ USA
}

\begin{abstract}
Dry sliding wear behavior of epoxy matrix syntactic foams filled with 20, 40 and 60 weight $\%$ fly ash cenosphere is reported based on response surface methodology. Empirical models are constructed and validated based on analysis of variance. Results show that syntactic foams have
\end{abstract}

*Corresponding author, Email: ngupta@nyu.edu, Ph: 718-260 3080 
higher wear resistance than the matrix resin. Among the parameters studied, the applied normal load $(\mathrm{F})$ had a prominent effect on wear rate, specific wear rate $\left(\mathrm{w}_{\mathrm{s}}\right)$ and coefficient of friction $(\mu)$. With increasing $\mathrm{F}$, the wear rate increased, whereas $\mathrm{w}_{\mathrm{s}}$ and $\mu$ decreased. With increase in filler content, the wear rate and $\mathrm{w}_{\mathrm{s}}$ decreased, while the $\mu$ increased. With increase in sliding velocity as well as sliding distance, the wear rate and $\mathrm{w}_{\mathrm{s}}$ show decreasing trends. Microscopy revealed broken cenospheres forming debris and extensive deformation marks on the wear surface.

Keywords: cenosphere; wear; syntactic foam; response surface methodology.

\section{Introduction}

Lightweight polymer matrix composites offer advantage of high specific strength and stiffness, which are important for weight sensitive structures. Hollow particle filled porous composites, called syntactic foams, are a class of particulate composites that are finding applications in marine and aircraft structures due to their lightweight combined with high damage tolerance, capability of keeping damage localized and possibility of simultaneously tailoring a variety of mechanical and thermal properties $[1,2]$. Increasing use of syntactic foams in automotive and aerospace applications requires understanding their tribological properties. Although detailed studies on wear behavior of metal matrix syntactic foams are available [3-6], similar studies on polymer matrix syntactic foams are relatively scarce [7-9]. In addition, due to a large number of parameter involved in wear testing, a clear understanding of structure-property correlations requires considerable additional effort. 
Inclusion of organic and inorganic fillers, and fibres of glass, carbon and aramid improves the wear performance of polymers, for example, see $[10,11]$. It has been reported that addition of nano $\mathrm{Al}_{2} \mathrm{O}_{3}, \mathrm{SiC}, \mathrm{CuO}, \mathrm{TiO}_{2}, \mathrm{ZnO}$ and $\mathrm{ZrO}_{2}$ can improve the wear resistance of polymers [1217]. The micro and nanoscale particles used to improve mechanical properties can also improve the wear resistance $[14,18]$. There is a significant interest in finding lighter weight and lower cost fillers to reduce the overall density and cost of the composites, while improving their tribological properties. One of the low cost fillers is fly ash, which is obtained as a waste byproduct from thermal power plants $[19,20]$. Finding applications for this waste material can also help environment. Fly ash contains hollow microspheres called cenospheres, which primarily consist of silica and alumina [21,22]. Cenospheres have been dispersed in different matrices like cement, polyester and epoxy resins for producing syntactic foams [23, 24]. Low cost of cenospheres can make syntactic foams economical [25] while improving the mechanical and thermal characteristics.

Considerable differences are likely in the tribological properties and wear mechanisms of composites containing hollow particles compared to those reinforced with solid particles. Partial wear can open up the void enclosed inside the hollow particles, where debris can accumulate. Thin walls of hollow particles may shear off easily. Therefore, detailed investigations of hollow particle filled composites are desired to understand the mechanisms of wear and damage. Some of the existing studies on metal matrix syntactic foams have touched upon these issues. The craters on the specimen surface due to the breakage of cenospheres were found to play a significant role in the dry sliding wear process in $\mathrm{Al} /$ cenosphere syntactic foams [3]. 
Table 1 summarizes the studies found in the literature where cenosphere filled polymer matrix composites are studied for tribological properties [8, 9, 26-28]. Wear behavior of cenosphere filled vinyl ester and polyester matrix syntactic foams has been reported [7-9]. Chauhan et al. [8] studied the friction and wear characteristics of vinyl ester/cenosphere syntactic foams under dry sliding conditions for different cenosphere sizes, applied loads and sliding speeds. It was found that the submicron and micro-sized cenospheres are capable of improving mechanical properties and wear resistance of syntactic foams. Chand et al. [26] studied the abrasive wear behavior of silane treated low density polyethylene (LDPE)/cenospheres syntactic foams and found that 10 weight $\%$ of cenospheres was optimum to obtain high mechanical and tribological properties.

In the existing literature, no methodical work is found on wear of epoxy/cenosphere syntactic foams, which is the focus of this work. Tribological behaviour is investigated by conducting experiments on Pin-on-disc tribometer. Further, based on the experimental values, Response Surface Methodology (RSM) based models of wear rate, specific wear rate (wear rate per unit load) and coefficient of friction (COF) are developed with reduced number of experiments using full factorial design (FFD). These models are used for interpolation between the scarce experimental data to capture the trend. Later, the ANOVA scheme is used which allows conducting experiments to investigate the independent effect of each parameter on the response. These empirical models are useful in observing the overall trend. This experimental design scheme allows the study of interactions among the process parameters. Table 1 also shows that all the studies on vinyl ester matrix syntactic foams have used cenospheres without any surface treatment or compatibilization. In order to directly compare the results of the present study on epoxy-cenosphere composite with the existing observations, no surface treatment is applied to 
cenospheres used in the present work. However, it is recognized that alteration of cenosphere surface compatibility or change in the particle-matrix interfacial strength may affect the result on wear properties, which may be focus of the future studies. The effects of sliding velocity, normal load, sliding distance and filler content on friction and sliding wear are analysed.

\section{Response Surface Methodology}

RSM is an accumulation of mathematical and statistical techniques for building empirical models. RSM has been widely used in wear studies [29-31]. In this methodology, the objective is to optimize a response (output variable), which is influenced by several independent input variables [29-31]. Using FFD, the mathematical model of any desired response to many input process parameters can be developed. The RSM is also used to recognize the influence of interactions among process parameters on performance criterion when they are varied concurrently. The independent process parameters are characterized in quantitative form and the response can be written as $[30,31]$

$$
\mathrm{Y}=\varphi\left(\mathrm{x}_{1}, \mathrm{x}_{2}, \mathrm{x}_{3}, \ldots \ldots \mathrm{x}_{\mathrm{k}}\right)
$$

where $\mathrm{Y}$ is the response, $\mathrm{X}_{1}, \mathrm{X}_{2}, \mathrm{x}_{3}, \ldots \ldots . . \mathrm{x}_{\mathrm{k}}$ are the input process parameters and $\varphi$ is the response function. $\varphi$ can be approximated by a polynomial when the mathematical form of function is unknown. This technique allows exploration of the relationships between independent and dependent variables. 


\section{Materials and methods}

\subsection{Materials}

Diglycidyl ether of bisphenol A based epoxy resin (LAPOX L-12) is used as the matrix resin with a room temperature curing polyamine hardener (K-6) containing a tetra-amine functional group, both supplied by Yuje Marketing, Bangalore, India. Cenospheres obtained from Cenosphere India Pvt., Ltd., Kolkata, India, are used as the filler. Chemical, physical and sieve analysis results of cenospheres are listed in Table 2.

Syntactic foams were prepared using 20, 40 and 60 weight $\%$ cenospheres. Measured quantity of epoxy resin was taken in a beaker to which the cenospheres were added. The mixture was gently stirred to obtain a homogenous mixture. Subsequently, hardener was added to the mixture and stirred gently. The slurry was cast in an aluminium mould of dimensions $100 \times 100 \times 16 \mathrm{~mm}^{3}$ and was allowed to cure for 24 hours at room temperature. The mould was coated with silicone releasing agent for easy removal of cast slabs. The specimens for the testing of dimension $12 \times$ $12 \times 25 \mathrm{~mm}$ (length $\times$ width $\times$ height $)$ were cut from the cast slabs using a diamond saw.

\subsection{Experimental procedure}

In the present work, sliding velocity (v), normal load (F), sliding distance (d) and filler content (R) are identified as the process parameters, which affect the responses, namely, wear rate $\left(\mathrm{w}_{\mathrm{t}}\right)$, specific wear rate $\left(\mathrm{w}_{\mathrm{s}}\right)$ and $\operatorname{COF}(\mu)$. Three levels for each of the four input parameters were selected for an initial pilot study. 81 trials based on FFD were planned [30, 31]. The process parameters and their levels are listed in Table 3 . The $12 \times 12 \mathrm{~mm}$ face of the sample was loaded 
against the disc with the loads of 10,30 and $50 \mathrm{~N}$, which correspond to initial contact pressure of 0.07, 0.21 and $0.35 \mathrm{MPa}$, respectively.

\subsection{Density measurement}

The density ( $\rho_{\text {ce }}$ ) of the specimens was experimentally measured using Archimedes principle by weighing the samples first in air and then in water. The theoretical density $\left(\rho_{c t}\right)$ is calculated by using rule of mixture

$$
\rho_{\mathrm{ct}}=\frac{1}{\left(\mathrm{~W}_{\mathrm{f}} / \rho_{\mathrm{f}}\right)+\left(\mathrm{W}_{\mathrm{m}} / \rho_{\mathrm{m}}\right)}
$$

where, $\mathrm{W}$ and $\rho$ represent the weight fraction and density, respectively. The suffixes $\mathrm{f}$ and $\mathrm{m}$ represent filler and matrix, respectively. The density of the epoxy matrix is $1162 \mathrm{~kg} / \mathrm{m}^{3}$. The volume fraction of matrix porosity $\left(\mathrm{V}_{\mathrm{v}}\right)$ in the syntactic foams is determined by

$$
V_{v}=\frac{\rho_{c t}-\rho_{c e}}{\rho_{c t}}
$$

Theoretical and experimental densities and matrix porosities are presented in Table 4. The matrix porosity is observed to increase with increasing particle content in the specimen. At very high cenosphere content, mixing becomes difficult and air entrapment between cenosphere particles in the matrix increases as observed in Table 4. The measured porosity values are similar to those observed in previous studies on polymer matrix syntactic foams [32].

\subsection{Sliding wear test}

Dry (unlubricated) sliding wear tests were carried out at ambient temperature using a pin-on-disc wear tester (DUCOM Instruments, Bangalore, India) according to ASTM G99-05 (2010) standard. A disc made of hardened chromium steel (EN-31, hardness 62 HRC) was used as the 
counter body against the pin. The test was conducted at $240 \mathrm{rpm}$ on tracks of different diameters of 40, 80 and $120 \mathrm{~mm}$. The other parameters varied in the experiment were the sliding velocity, load and sliding distance, as listed in Table 3. Since properties of the resin may depend on the strain rate, sliding velocity is limited to $1.5 \mathrm{~m} / \mathrm{s}$ to avoid effects related to strain rate sensitivity and heating effects. Prior to each test, the disc was cleaned with acetone and evenness of the disc surface is measured with the help of a dial indicator. The specimen was held stationary and the disc was rotated, while a normal force was applied through a lever mechanism. Dead weight (specified load) is mounted on the pan of the lever mechanism ensuring constant normal force. Prior to the tests, both pin and disc were polished against 600 grit SiC paper for keeping surface roughness parameter $\left(\mathrm{R}_{\mathrm{a}}=0.11 \mu \mathrm{m}\right)$ constant. Further, it ensures proper contact between the sample and the counter face. A computer-aided data acquisition system was used to simultaneously record both height loss (using inbuilt displacement transducer) and frictional force. The height loss is converted to the volume loss using the pin cross section area. The wear rate is defined as the volume loss per unit sliding distance.

The plot of volume loss against sliding distance is subjected to regression analysis to obtain the best-fit line, whose slope is equal to the wear rate. Thus, the steady state wear rate, $\mathrm{w}_{\mathrm{t}}$ is obtained from

$$
w_{t}=\frac{V_{C}-V_{B}}{d_{C}-d_{B}}
$$

where $V$ is the wear volume, $d$ is the sliding distance, subscripts $B$ and $C$ represent beginning and end of steady state wear. The wear resistance is defined as the reciprocal of wear rate

$$
W_{R}=w_{t}^{-1}
$$


The load bearing ability of the material is represented by the specific wear rate, $\mathrm{w}_{\mathrm{s}}$, which is defined as the wear rate per unit load

$$
\mathrm{w}_{\mathrm{s}}=\frac{W}{F}
$$

where $F$ is the normal load applied during wear test. $\mathrm{COF}(\mu)$ is defined as the ratio of tangential force needed to produce sliding to the normal force $\left(\mathrm{F}_{\mathrm{N}}\right)$ between the mating surfaces and is represented as

$$
\mu=\frac{F_{T}}{F_{N}}
$$

where $F_{T}$ is the tangential force obtained from the steady state wear regime.

\section{Results and Discussion}

Extensive scanning electron microscopy is conducted on the fabricated specimens. Figure 1 shows that the cenospheres are uniformly distributed in the syntactic foam microstructure and there are no clusters of either cenospheres or of matrix pores. Due to the presence of spherical particles in random distribution, the fabricated syntactic foams are isotropic. These microstructural observations taken on as-fabricated specimens will be useful in interpreting the results for the wear test specimens.

A representative set of results obtained from the wear testing are shown in Figure 2, where change in specimen height and frictional force are plotted with respect to the time. An initial transition period is observed after which the wear achieves a steady state as observed in this figure. The rate of specimen height loss remains along the same slope during the steady state. The wear mechanism for syntactic foams is schematically shown in Figure 3. Some cenospheres 
are partially cut on the initial wear surface, which tend to fill with the wear debris, corresponding to the initial transition zone observed in Figure 2a. Over a period of time, the rate of new cenospheres opening up for filling with debris and the older cenospheres wearing out and releasing the accumulated debris on the wear surface balance each other, providing the steady state observed in Figure 2a. Local fluctuations are observed in both height loss and frictional forces. These fluctuations can be attributed to the wear debris from cenosphere cavities coming in between the mating surfaces, which result in lifting the pin and providing lubricating effect.

\subsection{Effects of individual parameters}

The experimental values of $\mathrm{w}_{\mathrm{t}}, \mathrm{w}_{\mathrm{s}}$, and $\mu$ are presented in Table 5-Table 7 for three different sliding velocities of $0.5,1$ and $1.5 \mathrm{~m} / \mathrm{s}$, respectively. The values reported in these tables are average of three trials conducted under the same conditions. The standard deviation is not reported because three values are not enough to calculate reliable standard deviation values. In all cases, the variation among the three values was less than $4 \%$. Corresponding ANOVA results are presented in Table 8. The developed RSM models were also tested through coefficient of determination $(\mathrm{CoD})$ (Table 8), which is the proportion of variation in the parameter explained by the model. In case of wear rate and specific wear rate, $\mathrm{CoD}$ value is found to be high, which is desirable. COF is found to fluctuate with time leading to lower $\mathrm{CoD}$ value. The likely reason of the fluctuations is the generation of wear debris that can accumulate inside the partially broken cenospheres. After sufficient grinding of the cenosphere the debris will be released from the cenosphere cavity and make a film on which the pin can glide as represented in Figure 3. Formation of a low COF film, mainly of the matrix material, is known for fluctuations in the COF during dry sliding wear of composites [33]. To accommodate these fluctuations with 
respect to time, $95 \%$ confidence interval for COF is chosen in Table 8 instead of $99 \%$ set for the other parameters.

For neat epoxy, with increasing load and sliding distance specific wear rate and COF decreases, while rise in $\mathrm{w}_{\mathrm{s}}$ was observed with increasing sliding velocity [34, 35]. It is observed from the results that $\mathrm{w}_{\mathrm{t}}, \mathrm{w}_{\mathrm{s}}$, and $\mu$ decrease with increasing velocity. Previous studies on neat epoxy also observed that the specific wear rate increased with the normal load but decreased with the sliding velocity [36]. Only very few data points show anomalies in this large data set that shows results with respect to applied force, distance and cenosphere content. In syntactic foams, thin walled ceramic filler particles are used. The shear strength of these particles is very low compared to their hydrostatic compressive strength, for which they are primarily selected. Increase in the sliding velocity results in increase in the shear force on the particles. It is also observed that, at the same sliding velocity and applied force, increase in cenosphere content reduces the wear rate and specific wear rate, whereas the COF increases. Since polymer is the softer phase and has higher wear rate, increase in the ceramic content in the composite helps in reducing the wear rate of the composite as observed in the results. It is also noted that the wear of the cenospheres present on the surface of syntactic foams opens up their cavity. The cavity depth serves as the measure of surface roughness. Therefore, increased cenosphere content in syntactic foams results in higher $\mathrm{COF}$.

The scanning electron micrographs of a representative wear tested syntactic foam specimen (containing 60 weight $\%$ cenospheres, tested at $1.5 \mathrm{~m} / \mathrm{s}$ velocity, $50 \mathrm{~N}$ load, and $2000 \mathrm{~m}$ sliding distance) are shown in Figure 4. It is observed in Figure 4(a) that the entire specimen surface 
shows shear deformation marks. A closer observation in Figure 4(b) shows two broken cenosphere on the surface as a result of dry sliding wear. An intact cenosphere is visible in the subsurface region next to a broken particle. As the wear process continues and more of polymer and surface particles wear out, the subsurface particle will then start to wear and finally break. Figure 4(c) show that the broken cenosphere is surrounded by its debris embedded in the matrix material.

\subsection{Analytical models}

In the current study the independent variables are sliding velocity (v), normal load (F), sliding distance (d) and cenosphere content $(\mathrm{R})$ and the dependent variables are $\mathrm{w}_{\mathrm{t}}, \mathrm{w}_{\mathrm{s}}$ and $\mu$. The quadratic equation considering two-factor interactions is given in previous studies by [30, 31]

$$
\begin{aligned}
Y= & b_{0}+b_{1} v+b_{2} F+b_{3} d+b_{4} R+b_{11} v^{2}+b_{22} F^{2}+b_{33} d^{2}+b_{44} R^{2}+b_{12} v F+b_{13} v d+b_{14} v R \\
& +b_{23} F d+b_{24} F R+b_{34} d R
\end{aligned}
$$

where $\mathrm{Y}$ is the desired characteristic and $b_{0}, b_{1, \ldots} b_{34}$ are the regression coefficients to be determined. The regression coefficients of the quadratic model are determined by $[30,31]$

$$
\mathrm{b}=\left(\mathrm{X}^{\mathrm{T}} \mathrm{X}\right)^{-1} \mathrm{X}^{\mathrm{T}} \mathrm{Y}
$$

where $\mathrm{b}$ is the matrix of parameter estimates, $\mathrm{X}$ is the calculation matrix that includes linear, quadratic and interaction terms; and $\mathrm{X}^{\mathrm{T}}$ is the transpose of $\mathrm{X}$. The quadratic models are determined by multiple regression analysis $[30,31]$ based on the experimental values obtained in the testing to predict $\mathrm{w}_{\mathrm{t}}, \mathrm{w}_{\mathrm{s}}$ and $\mu$ by 


$$
\begin{aligned}
& \mathrm{w}_{\mathrm{t}}=10.15-(4.05 \times \mathrm{v})-\left(5.2 \times 10^{-3} \times \mathrm{F}\right)-\left(2.94 \times 10^{-3} \times \mathrm{d}\right)+\left(5.05 \times 10^{-3} \times \mathrm{R}\right) \\
& +\left(4.8 \times 10^{-1} \times \mathrm{v}^{2}\right)+\left(4.86 \times 10^{-4} \times \mathrm{F}^{2}\right)+\left(2.67 \times 10^{-7} \times \mathrm{d}^{2}\right)-\left(7.7 \times 10^{-4} \times \mathrm{R}^{2}\right) \\
& -\left(1.41 \times 10^{-3} \times \mathrm{v} \times \mathrm{F}\right)+\left(7.58 \times 10^{-4} \times \mathrm{v} \times \mathrm{d}\right)+\left(7.02 \times 10^{-3} \times \mathrm{v} \times \mathrm{R}\right)+\left(1.44 \times 10^{-5} \times \mathrm{F} \times \mathrm{D}\right) \\
& -\left(2 \times 10^{-4} \times \mathrm{F} \times \mathrm{R}\right)-\left(3.34 \times 10^{-6} \times \mathrm{d} \times \mathrm{R}\right) \\
& \mathrm{w}_{\mathrm{S}}=1.1-(0.29 \times \mathrm{v})-\left(2.71 \times 10^{-2} \times \mathrm{F}\right)-\left(1.7 \times 10^{-4} \times \mathrm{d}\right)-\left(1.85 \times 10^{-3} \times \mathrm{R}\right) \\
& +\left(3.15 \times 10^{-2} \times \mathrm{v}\right)+\left(1.95 \times 10^{-4} \times \mathrm{F}^{2}\right)+\left(7.95 \times 10^{-9} \times \mathrm{d}^{2}\right)-\left(5.5 \times 10^{-5} \times \mathrm{R}^{2}\right) \\
& +\left(2.84 \times 10^{-3} \times \mathrm{v} \times \mathrm{F}\right)+\left(2.37 \times 10^{-5} \times \mathrm{v} \times \mathrm{d}\right)+\left(6.79 \times 10^{-4} \times \mathrm{v} \times \mathrm{R}\right)+ \\
& \left(2.02 \times 10^{-6} \times \mathrm{F} \times \mathrm{d}\right)+\left(7.92 \times 10^{-5} \times \mathrm{F} \times \mathrm{R}\right)+\left(4.41 \times 10^{-7} \times \mathrm{d} \times \mathrm{R}\right) \\
& +\left(1.26 \times 10^{-5} \times \mathrm{v} \times \mathrm{d}\right)-\left(1.57 \times 10^{-3} \times \mathrm{v} \times \mathrm{R}\right)-\left(7.4 \times 10^{-7} \times \mathrm{F} \times \mathrm{d}\right)+\left(5.46 \times 10^{-5} \times \mathrm{F} \times \mathrm{R}\right) \\
& +\left(5.14 \times 10^{-8} \times \mathrm{d} \times \mathrm{R}\right) \\
& +1.05 \times 10^{-1} \times \mathrm{v}-\left(7.6 \times 10^{-5} \times \mathrm{F}^{2}\right)-\left(4 \times 10^{-8} \times \mathrm{d}^{2}\right)+\left(1.74 \times \mathrm{R}^{2}\right)+\left(2.8 \times 10^{-3} \times \mathrm{v} \times \mathrm{F}\right) \\
& +4.2 \times 10^{-1}-\left(3.2 \times 10^{-1} \times \mathrm{v}\right)+\left(8.8 \times 10^{-4} \times \mathrm{F}\right)+\left(1.9 \times 10^{-4} \times \mathrm{d}\right)-\left(5.5 \times 10^{-4} \times \mathrm{R}\right)
\end{aligned}
$$

where, $v$ is represented in $(\mathrm{m} / \mathrm{s}), \mathrm{F}$ in $(\mathrm{N}), \mathrm{d}$ in $(\mathrm{m}), \mathrm{R}$ in (weight\%), $\mathrm{w}_{\mathrm{t}}$ in $\left(\mathrm{mm}^{3} / \mathrm{km}\right)$ and $\mathrm{w}_{\mathrm{s}}$ in $\left(\mathrm{mm}^{3} / \mathrm{N}-\mathrm{km}\right)$.

The applicability of the developed models represented by equations (10)-(12) was confirmed through analysis of variance (ANOVA) [30, 31]. As per ANOVA, the computed value of F-ratio of developed model should be more than the F-table of the model to be adequate for a specified confidence interval. 
The RSM model equations (10)-(12) are used to predict $\mathrm{w}_{\mathrm{t}}, \mathrm{w}_{\mathrm{s}}$ and $\mu$ of syntactic foams by substituting the appropriate values of $\mathrm{v}, \mathrm{F}, \mathrm{d}$ and $\mathrm{R}$ to identify the parameter that has the most dominant influence on $\mathrm{w}_{\mathrm{t}}, \mathrm{w}_{\mathrm{s}}$ and $\mu$. This was achieved using the equations by varying one parameter at a time, while the other parameters were assigned the middle value in their selected range of values. The results of this parametric study are presented in Figure 5, Figure 6 and Figure 7 for $\mathrm{w}_{\mathrm{t}}, \mathrm{w}_{\mathrm{s}}$ and $\mu$, respectively. These graphs can be used as a quick reference to understand the general trends between various parameters. It is observed in Figure 5(a) that the wear rate increases with increasing applied force but decreases with increasing velocity. Similarly, Figure 5(b) shows that the wear rate decreases with increasing both filler content and sliding distance. Figure 6 shows that the specific wear rate decreases with all four parameters namely sliding velocity, applied force, filler content and sliding distance. However, the rate of decrease for each of these parameters with $\mathrm{w}_{\mathrm{s}}$ is different. The trends show that the lightweight syntactic foams containing high cenosphere weight fraction can be beneficial in applications where weight reduction is required. Figure 7(a) shows the trend of COF, where it is observed that COF decreases with increasing applied force and sliding velocity. COF shows saturation with the sliding velocities of over $1 \mathrm{~m} / \mathrm{s}$ for the tested material system. Figure 7(b) shows that COF increases with increasing filler content and sliding distance. It is anticipated that some of these results such as the trend with the sliding velocity may change with surface roughness, which is not a parameter for study in this work. 


\subsection{Effects of two parameter interactions}

Table 9 shows that matrix used for studying the two parameter interaction effects in syntactic foams. The results are presented in Figure 8 - Figure 10. These graphs are plotted taking into consideration of two parameters at a time, while the other two parameters are fixed at middle level. Equations (10)-(12) are used to develop the interaction plots shown in Figure 8 - Figure 10.

\subsubsection{Wear rate}

Figure 8 illustrate the interaction effects of process parameters on $\mathrm{w}_{\mathrm{t}}$. It is observed in Figure 8(a)-(c) that the wear rate monotonically decreases with sliding velocity for any specified value of normal load, sliding distance or cenosphere content. Figure 8(a) shows that the wear rate increases with the applied load. Further, it is observed from Figure 8(b) and (c) that the wear rate decreases with increase in sliding distance and cenosphere content. These graphs can be useful in selecting a combination of parameters that can provide low wear rate.

Cenospheres, comprising brittle alumino-silicates, are broken into fine particles and mixed over the wear surface with the resin [3]. Higher normal load likely leads to increased fracture of particles, generating more abrasive material, which results in increased wear rate. A similar effect of normal load on volumetric wear rate was observed on epoxy matrix composites by Kanchanomai et.al. [37].

Figure $8(\mathrm{~b})$ shows that the sensitivity of $\mathrm{w}_{\mathrm{t}}$ to sliding distance decreases as the sliding velocity increases. For increasing the sliding velocity from 0.5 to $1.5 \mathrm{~m} / \mathrm{s}$, the wear rate for 1000 and $3000 \mathrm{~m}$ sliding distances decrease by 37 and $15.8 \%$, respectively. Fracture of surface asperities 
at a given surface finish level is likely contributor to the high initial wear rate $[8,38]$. As wear progresses, the surfaces of both epoxy and cenospheres are smoothened resulting in reduced wear rate. It has been reported that with increasing sliding distance the effective contact area, surface roughness and surface chemistry change, resulting in deviation in wear rate [39].

Figure $8(\mathrm{c})$ shows that $\mathrm{w}_{\mathrm{t}}$ decreases with increasing sliding velocity and cenosphere content. These observations on syntactic foams are in good agreement with the available literature [40]. The wear rate of polymer composites is influenced by the formation of a transfer film on the counter face when a polymer slides against the material, leading to reduced $\mathrm{w}_{\mathrm{t}}[8,13,18]$. The wear rate is plotted as a function of cenosphere content at different normal loads in Figure 8(d). The wear rate decreases with increase in filler content for given load value and increases with increased applied load. It is noted that $\mathrm{w}_{\mathrm{t}}$ remains nearly constant for up to 40 weight $\%$ cenospheres at 40 and $50 \mathrm{~N}$ applied loads. It is likely that the applied load of $40 \mathrm{~N}$ is enough to compress the surface asperities and reduce the dependence of wear on the initial surface conditions and provide a more stable wear rate [41]. This is further corroborated in Figure 8(e), where $\mathrm{w}_{\mathrm{t}}$ decreases with sliding distance and tends to reach a steady state after certain sliding distance at higher loads. The distance for reaching steady state reduces with increasing load. For $50 \mathrm{~N}$ load, the steady state is reached after $2000 \mathrm{~m}$, whereas the steady state is reached at longer sliding distances at lower loads. Interaction between $\mathrm{w}_{\mathrm{t}}$ and sliding distance at different filler contents is shown in Figure 8(f). The wear rate decreases with sliding distance for given cenosphere content. It also decreases with increasing cenosphere content. 


\subsubsection{Specific wear rate}

Normalizing wear rate with the applied load can provide further clarity in the trends. Specific wear rate with respect to sliding velocity is plotted in Figure 9(a)-(c) for applied force, sliding distance, and filler content. It is observed that $\mathrm{w}_{\mathrm{s}}$ decreases with increasing sliding velocity as each of these parameters increase. The normalization reveals that although $\mathrm{w}_{\mathrm{t}}$ is the highest at 50 $\mathrm{N}$ applied load, $\mathrm{w}_{\mathrm{s}}$ is the lowest for this load. The effects of sliding distance and filler content on specific wear rate are similar to those observed on wear rate. The combination of higher sliding velocity with high applied normal load is advantageous in minimizing the specific wear rate. Figure 9(d) shows that the increase in cenosphere content also reduces $\mathrm{w}_{\mathrm{s}}$, which implies that the high cenosphere content is desirable for both $\mathrm{w}_{\mathrm{t}}$ and $\mathrm{w}_{\mathrm{s}}$ to be low.

A comparison of Figure 8(d) and Figure 9(d) reveals that the load normalized $\mathrm{w}_{\mathrm{s}}$ reduces as the applied force is increased. It is observed that for 40 and $50 \mathrm{~N}$ loads, $\mathrm{w}_{\mathrm{s}}$ is almost unchanged up to filler content of 40 weight $\%$. It is expected that the wear mechanism is dominated by the matrix behavior until this point. Above 40 weight $\%$, the filler content is high enough to play a significant role. These results are similar to previous observations [42-45]. Figure 9(e) provides further insight that the sliding distance does not have a significant influence on $\mathrm{w}_{\mathrm{s}}$ above a critical load, which for this material seems to be 40 N. A comparison of Figure 9(e) and (f) reveals that a combination of high cenosphere content and high applied load are useful in obtaining low $\mathrm{w}_{\mathrm{s}}$ in epoxy/cenosphere syntactic foams. 


\subsubsection{Coefficient of Friction}

The variation of $\mu$ is displayed in Figure 10 for various study parameters. As a general observation, most trends are not monotonous and show a range of parameters where $\mu$ can be minimized. The effect of sliding velocity on $\mu$ can be observed in Figure 10(a)-(c) for variation in applied load, sliding distance, and cenosphere content. It is observed that $\mu$ can be minimized in the sliding velocity range of $1-1.5 \mathrm{~m} / \mathrm{s}$. Slower than $1 \mathrm{~m} / \mathrm{s}$ velocities provide high $\mu$ for all applied loads, cenosphere contents and sliding distances.

The lowest $\mu$ was observed at a combination of $1 \mathrm{~m} / \mathrm{s}$ sliding velocity with $50 \mathrm{~N}$ applied normal load. Also, it is observed in Figure 10(c) that $\mu$ increases with filler content. Epoxy is the softer phase in the composite and high volume fraction of epoxy is useful in creating a lubricating film of low $\mu$. At high cenosphere content, the probability of having some broken cenospheres at the surface is high, which increases the surface roughness and results in high $\mu$. Figure 10(d) shows that $\mu$ is lower for higher values of applied load. $\mu$ does not show any appreciable change with respect to cenosphere content at 10 and $20 \mathrm{~N}$ applied loads. These low values of loads are not high enough to press the pin on the disk. It is likely that the pin glides over disk making only point contacts, leading to nearly the same $\mu$ for all filler contents. As the applied load increases, the effect of presence of cenosphere increases on $\mu$ as observed in this figure.

Further, Figure 10(e) shows that irrespective of the applied normal load, $\mu$ increases with sliding distance; reaches the maximum value and then starts to reduce again under the dry sliding conditions. However, with increased applied load, $\mu$ decreases, as also observed previously [46]. 
A combination of Figure 10(e) and (f) shows that the low applied load and high cenosphere content give the highest value of $\mu$ around sliding distance of $2200 \mathrm{~m}$.

The normal probability plots of the residual for $\mathrm{w}_{\mathrm{t}}, \mathrm{w}_{\mathrm{s}}$ and $\mu$ are presented in Figure 11. These plots show normal error distribution except for a few in the points in the beginning and end. The proposed model can be used to predict the wear parameters of cenosphere/epoxy syntactic foams within the limits of the factors studied. Figure 12 shows the comparison between measured and predicted values for wear rate, specific wear rate and coefficient of friction. Average error for $\mu$ is relatively on higher side for the reasons mentioned earlier. Variations in all the cases are likely due to the material parameters associated with cenospheres like, wall porosity, wall thickness variation within one particle, surface defects and variations in sphericity of particles. Nevertheless, utilisation of these environmental pollutants in wear scenarios for developing composite materials can be useful.

\section{Conclusions}

Epoxy matrix syntactic foams were fabricated with 20, 40 and 60 weight $\%$ cenospheres and the dry sliding wear characteristics were studied as per full factorial design of experiments. The influence of sliding velocity, normal load, sliding distance and filler content are analysed on wear rate, specific wear rate and coefficient of friction $(\mu)$ through response surface methodology based quadratic models. Effect of each variable and effects of interaction between two variables on the wear properties were analysed. The results show that

- With increasing applied normal load, the wear rate increased, whereas the specific wear rate and $\mu$ decreased. 
- With increase in filler content, the wear rate and specific wear rate decreased, while the $\mu$ increased.

- With increase in sliding velocity as well as sliding distance, the wear rate and specific wear rate show decreasing trends. $\mu$ decreases with sliding velocity at the same cenosphere content. However, at low cenosphere contents of up to 30 weight $\%, \mu$ shows a minima around sliding velocities of $1-1.2 \mathrm{~m} / \mathrm{s}$.

- $\mu$ shows maximum values at sliding distance of $2200 \mathrm{~m}$ when plotted for different applied force and cenosphere contents. The highest $\mu$ value is found at low applied load and high cenosphere content.

The results of this study can be used to select material composition as per the tribological requirement of the component. Selection of appropriate material can reduce the wear rate as well as reduce the density of the material. It is further expected that the lubricated wear behavior of the same materials may be different and such information needs to be investigated in subsequent studies.

\section{Acknowledgments}

Authors acknowledge the support provided by BVB College of Engineering and Technology, Hubli, Karnataka, India, under Research Experience for Undergraduates (REU) program. Authors are grateful to Management, Dr. Ashok Shettar (Principal) and Dr. P. G. Tewari (Head, Mechanical Engineering) for the encouragement and support. The author NG acknowledges support by Office of Naval Research grant N00014-10-1-0988. The opinions of the authors expressed herein do not necessarily state or reflect those of the United States Government or the ONR, and shall not be used for advertising or product endorsement purposes. 


\section{References}

1. Gupta, N., Zeltmann, S.E., Shunmugasamy, V.C., and Pinisetty, D., Applications of polymer matrix syntactic foams. JOM-Journal of the Minerals, Metals and Materials Society, 2014. 66(2): p. 245-254.

2. Gupta, N., Pinisetty, D., and Shunmugasamy, V.C., Reinforced Polymer Matrix Syntactic Foams: Effect of Nano and Micro-Scale Reinforcement, . 2013: SpringerBriefs in Materials, Springer, NY.

3. Mondal, D.P., Das, S., and Jha, N., Dry sliding wear behaviour of aluminum syntactic foam. Materials \& Design, 2009. 30(7): p. 2563-2568.

4. Jha, N., Badkul, A., Mondal, D.P., Das, S., and Singh, M., Sliding wear behaviour of aluminum syntactic foam: A comparison with Al-10wt\% SiC composites. Tribology International, 201144 (3): p. 220-231.

5. Uthayakumar, M., Kumaran, S.T., and Aravindan, S., Dry Sliding Friction and Wear Studies of Fly Ash Reinforced AA-6351 Metal Matrix Composites. Advances in Tribology, 2013. 2013: p. Article ID 365602-6 pages.

6. Sudarshan and Surappa, M.K., Dry sliding wear of fly ash particle reinforced A356 Al composites. Wear, 2008. 265(3-4): p. 349-360.

7. Chauhan, S.R. and Thakur, S., Effect of micro-size cenosphere content on friction and dry sliding wear behavior of vinylester composites - A Taguchi method. Advanced Materials Research, 2012. 585: p. 569-573.

8. Chauhan, S.R. and Thakur, S., Effects of particle size, particle loading and sliding distance on the friction and wear properties of cenosphere particulate filled vinylester composites. Materials \& Design, 2013. 51(0): p. 398-408. 
9. Singh, A.K. and Siddhartha, Leverage of cenosphere filler size on mechanical and dry sliding wear peculiarity of polyester composites. Journal of Composite Materials, 2014. in press(doi: 10.1177/0021998314554436).

10. Sawyer, W.G., Freudenberg, K.D., Bhimaraj, P., and Schadler, L.S., A study on the friction and wear behavior of PTFE filled with alumina nanoparticles. Wear, 2003. 254(5-6): p. 573-580.

11. Axen, N., Hogmark, S., and Jacobson, S., Friction and wear measurement techniques, in Modern tribology handbook, B. Bhushan, Editor. 2000, CRC Press: London. p. 493-510.

12. Lin, J.-C., Compression and wear behavior of composites filled with various nanoparticles. Composites Part B: Engineering, 2007. 38(1): p. 79-85.

13. Bahadur, S. and Sunkara, C., Effect of transfer film structure, composition and bonding on the tribological behavior of polyphenylene sulfide filled with nano particles of TiO2, $\mathrm{ZnO}, \mathrm{CuO}$ and $\mathrm{SiC}$. Wear, 2005. 258(9): p. 1411-1421.

14. Wetzel, B., Haupert, F., Friedrich, K., Zhang, M.Q., and Rong, M.Z., Impact and wear resistance of polymer nanocomposites at low filler content. Polymer Engineering \& Science, 2002. 42(9): p. 1919-1927.

15. Kurahatti, R.V., Surendranathan, A.O., Srivastava, S., Singh, N., Ramesh Kumar, A.V., and Suresha, B., Role of zirconia filler on friction and dry sliding wear behaviour of bismaleimide nanocomposites. Materials \& Design, 2011. 32(5): p. 2644-2649.

16. Li, F., Hu, K.-a., Li, J.-1., and Zhao, B.-y., The friction and wear characteristics of nanometer ZnO filled polytetrafluoroethylene. Wear, 2001. 249(10-11): p. 877-882. 
17. Chang, L., Zhang, Z., Ye, L., and Friedrich, K., Tribological properties of high temperature resistant polymer composites with fine particles. Tribology International, 2007. 40(7): p. 1170-1178.

18. Xing, X.S. and Li, R.K.Y., Wear behavior of epoxy matrix composites filled with uniform sized sub-micron spherical silica particles. Wear, 2004. 256(1-2): p. 21-26.

19. Gupta, N., Singh Brar, B., and Woldesenbet, E., Effect of filler addition on the compressive and impact properties of glass fibre reinforced epoxy. Bulletin of Materials Science, 2001. 24(2): p. 219-223.

20. Rohatgi, P.K., Weiss, D., and Gupta, N., Applications of fly ash in synthesizing low-cost MMCs for automotive and other applications. JOM, 2006. 58(11): p. 71-76.

21. Scott, W.D., Heldt, T., Van Erp, G., and Ayers, S.R., Vinyl ester/cenosphere composite materials for civil and structural engineering. Fiber Reinforced Polymer International, 2005. 2(3): p. 2-5.

22. Cardoso, R.J., Shukla, A., and Bose, A., Effect of particle size and surface treatment on constitutive properties of polyester-cenosphere composites. Journal of Materials Science, 2002. 37(3): p. 603-613.

23. Devi, M.S., Murugesan, V., Rengaraj, K., and Anand, P., Utilization of flyash as filler for unsaturated polyester resin. Journal of Applied Polymer Science, 1998. 69(7): p. 13851391.

24. Labella, M., Zeltmann, S.E., Shunmugasamy, V.C., Gupta, N., and Rohatgi, P.K., Mechanical and thermal properties of fly ash/vinyl ester syntactic foams. Fuel, 2014. 121: p. $240-249$. 
25. Deepthi, M.V., Sharma, M., Sailaja, R.R.N., Anantha, P., Sampathkumaran, P., and Seetharamu, S., Mechanical and thermal characteristics of high density polyethylene-fly ash Cenospheres composites. Materials \& Design, 2010. 31(4): p. 2051-2060.

26. Chand, N., Sharma, P., and Fahim, M., Abrasive wear behavior of LDPE Filled with silane treated flyash cenospheres. Composite Interfaces 2011. 18(7): p. 575-586.

27. Ray, D. and Gnanamoorthy, R., Friction and Wear Behavior of Vinylester Resin Matrix Composites Filled with Fly Ash Particles. Journal of Reinforced Plastics and Composites, 2007. 26(1): p. 5-13.

28. Thakur, S. and Chauhan, S.R., Study on mechanical and tribological behavior of cenosphere filled vinylester composites - A Taguchi method. Indian Journal of Engineering \& Materials Sciences, 2013. 20: p. 539-548.

29. Noordin, M.Y., Venkatesh, V.C., Sharif, S., Elting, S., and Abdullah, A., Application of response surface methodology in describing the performance of coated carbide tools when turning AISI 1045 steel. Journal of Materials Processing Technology, 2004. 145(1): p. 46-58.

30. Montgomery, D.C., Design and analysis of experiments, . 2003, New York: John Wiley and Sons.

31. Myers, R.H., Montgomery, D.C., and Anderson-Cook, C.M., Response surface methodology: Process and product optimization using designed experiments, . 2009, New York: John Wiley and Sons, Inc.

32. Gupta, N., Ye, R., and Porfiri, M., Comparison of tensile and compressive characteristics of vinyl ester/glass microballoon syntactic foams. Composites Part B: Engineering, 2010. 41(3): p. 236-245. 
33. Ravikiran, A. and Surappa, M.K., Oscillations in coefficient of friction during dry sliding of A356 Al-30\% WT SiCp MMC against steel. Scripta Materialia, 1997. 36(1): p. 95-98.

34. Sudheer, M., Prabhu, R., Raju, K., and Bhat, T., Effect of Filler Content on the Performance of Epoxy/PTW Composites. Advances in Materials Science and Engineering, 2014,. 2014,: p. Article ID 970468, 11 pages.

35. Nirmal, U., Hashim, J., and Low, K.O., Adhesive wear and frictional performance of bamboo fibres reinforced epoxy composite. Tribology International, 2012. 47: p. 122133.

36. Smerdova, O., Mazuyer, D., and Cayer-Barrioz, J., Links between energy dissipation and wear mechanisms in solid epoxy/epoxy sliding contact. Tribology International, 2014. 77(0): p. 148-159.

37. Kanchanomai, C., Noraphaiphipaksa, N., and Mutoh, Y., Wear characteristic of epoxy resin filled with crushed-silica particles. Composites Part B: Engineering, 2011. 42(6): p. 1446-1452.

38. Siddhartha, Patnaik, A., and Bhatt, A.D., Mechanical and dry sliding wear characterization of epoxy-TiO2 particulate filled functionally graded composites materials using Taguchi design of experiment. Materials \& Design, 2011. 32(2): p. 615627.

39. Rao, R.N. and Das, S., Effect of sliding distance on the wear and friction behavior of as cast and heat-treated Al-SiCp composites. Materials \& Design, 2011. 32(5): p. 30513058. 
40. Chauhan, S.R. and Thakur, S., Effect of micro size cenosphere particles reinforcement on tribological characteristics of vinylester composites under dry sliding conditions. Journal of Minerals and Materials Characterization and Engineering, 2012. 11: p. 938-946.

41. Siddhartha and Gupta, K., Mechanical and abrasive wear characterization of bidirectional and chopped E-glass fiber reinforced composite materials. Materials \& Design, 2012. 35(0): p. 467-479.

42. Arivalagan, P., Suresha, B., Chandramohan, G., Krishnaraj, V., and Palaniappan, N., Mechanical and abrasive wear behavior of carbon fabric reinforced epoxy composite with and without fly ash cenospheres. Journal of Composite Materials, 2013. 47(23): p. 2925-2935.

43. Zhang, M.Q., Rong, M.Z., Yu, S.L., Wetzel, B., and Friedrich, K., Effect of particle surface treatment on the tribological performance of epoxy based nanocomposites. Wear, 2002. 253(9-10): p. 1086-1093.

44. Jawahar, P., Gnanamoorthy, R., and Balasubramanian, M., Tribological behaviour of clay - thermoset polyester nanocomposites. Wear, 2006. 261(7-8): p. 835-840.

45. Friedrich, K., Zhang, Z., and Schlarb, A.K., Effects of various fillers on the sliding wear of polymer composites. Composites Science and Technology, 2005. 65(15-16): p. 23292343.

46. Jia, B.-B., Li, T.-S., Liu, X.-J., and Cong, P.-H., Tribological behaviors of several polymer-polymer sliding combinations under dry friction and oil-lubricated conditions. Wear, 2007. 262(11-12): p. 1353-1359. 
Table 1. Literature review on cenosphere filled syntactic foams. Untreated cenospheres are used in all studies except for the one marked with *.

\begin{tabular}{|c|c|c|c|c|}
\hline Ref. & Matrix & $\begin{array}{l}\text { Particle } \\
\text { Properties }\end{array}$ & $\begin{array}{l}\text { Wear } \\
\text { Parameters }\end{array}$ & Results \\
\hline [8] & Vinylester & $\begin{array}{l}\Phi=2 \mu \mathrm{m}, \quad 900 \\
\mathrm{~nm} \text { and } 400 \mathrm{~nm} \\
\rho_{c}=0.4-0.6 \\
\left.\mathrm{~g} / \mathrm{cm}^{3}\right) \\
\mathrm{R}=2, \quad 6, \quad 10 \\
\text { weight\% }\end{array}$ & $\begin{array}{l}\mathrm{L}=5, \quad 10, \quad 15, \\
20,25 \mathrm{~km} \\
\mathrm{~N}=10,70 \mathrm{~N} \\
\mathrm{v}=1.9 \quad, \quad 5 \cdot 7 \\
\mathrm{~m} / \mathrm{s}\end{array}$ & $\begin{array}{l}\text { 1. The submicron sized particles are more effective } \\
\text { in improving the wear resistance as compared to } \\
\text { the microsized particles. } \\
\text { 2. Composites with } 6 \text { weight\% submicron sized } \\
\text { particles have the lowest specific wear rate. } \\
\text { 3. The highest wear rate is observed at } \mathrm{N}=10 \mathrm{~N} \text {, } \\
\mathrm{v}=1.9 \mathrm{~m} / \mathrm{s} \Phi=2 \mu \mathrm{m} \text {. Lowest wear rate is at } \mathrm{N}=70 \\
\mathrm{~N}, \mathrm{~V}=1.9 \mathrm{~m} / \mathrm{s} \text { and } \Phi=400 \mathrm{~nm} \text {. } \\
\text { 4. } 400 \mathrm{~nm} \text { diameter cenospheres are most effective } \\
\text { in reducing COF and specific wear rate. }\end{array}$ \\
\hline [9] & Polyester & $\begin{array}{l}\Phi=900 \mathrm{~nm}, \rho_{c} \\
=0.67 \mathrm{~g} / \mathrm{cm}^{3} ; \\
\Phi=600 \mathrm{~nm}, \rho_{c} \\
=0.65 \mathrm{~g} / \mathrm{cm}^{3} ; \\
\Phi=300 \mathrm{~nm}, \rho_{c} \\
=0.64 \mathrm{~g} / \mathrm{cm}^{3} \\
\mathrm{R}=10 \text { weight } \%\end{array}$ & $\begin{array}{l}\mathrm{L}=1,2,3,4 \\
\mathrm{~km} \\
\mathrm{v}=1.57,2.62, \\
3.66, \quad 4.71 \\
\mathrm{~m} / \mathrm{s} \\
\mathrm{N}=10,20,30 \\
40 \mathrm{~N}\end{array}$ & $\begin{array}{l}\text { 1. } 300 \mathrm{~nm} \text { size cenospheres filled composite shows } \\
\text { high wear resistance. } \\
\text { 2. The COF and specific wear rate of neat polyester } \\
\text { are higher compared to submicron size } \\
\text { cenosphere particulate-filled composites. } \\
\text { 3. COF and specific wear rate of cenosphere-filled } \\
\text { composites decrease with increase in normal } \\
\text { load and sliding velocity but increase with } \\
\text { sliding distance. }\end{array}$ \\
\hline [26] & LDPE & $\begin{array}{l}\Phi<355 \mu \mathrm{m}^{*} \\
\mathrm{R}=10,15,20 \\
\text { weight\% }\end{array}$ & $\begin{array}{l}\mathrm{N}=10 \mathrm{~N} \\
\mathrm{v}=0.314 \\
0.628,0.942 \\
\mathrm{~m} / \mathrm{s} \\
\text { Contact } \\
\text { pressure } \times \mathrm{v}= \\
0.062, \mathrm{O} .124 \\
0.187 \mathrm{MPa} \\
\mathrm{m} / \mathrm{s}\end{array}$ & $\begin{array}{l}\text { 1. Wear rate increases with the increase in speed } \\
\text { and weight concentration of cenospheres when } \\
\text { applied load and sliding duration are kept } \\
\text { constant. } \\
\text { 2. Abrasive wear resistance of LDPE cenosphere } \\
\text { composite is greatly increased on silane } \\
\text { treatment of cenospheres. } \\
\text { 3. } 10 \text { weight\% silane treated LDPE/cenosphere } \\
\text { composite showed the highest wear resistance. }\end{array}$ \\
\hline [27] & Vinylester & $\begin{array}{l}\mathrm{R}=4 \mathrm{O} \\
\text { weight\% }\end{array}$ & $\begin{array}{l}\mathrm{N}=5,7 \cdot 5,10 \\
\mathrm{~N} \\
\mathrm{v}=0.2 \quad \mathrm{~m} / \mathrm{s} \\
\text { Radial } \\
\text { distance }(35, \\
30,25 \mathrm{~mm}) \\
\omega=50,65,80 \\
\text { rpm }\end{array}$ & $\begin{array}{l}\text { 1. Unfilled resin had a } 443,535 \text { and } 751 \% \text { higher } \\
\text { weight loss compared to the } 40 \% \text { composites at } \\
\text { all applied normal loads. } \\
\text { 2. Wear of resin increased with the sliding distance. } \\
\text { 3. The COF of composites was lower than that of } \\
\text { neat resin. } \\
\text { 4. Syntactic foam containing } 40 \% \text { particles had had } \\
\text { a lower weight loss, linear wear and a COF } \\
\text { compared to the 50\% composites. } \\
\text { 5. The optimum combination of strength and } \\
\text { higher energy absorption of } 40 \% \text { composites } \\
\text { made them more wear resistant than the } 50 \% \\
\text { composites. }\end{array}$ \\
\hline [28] & Vinylester & $\begin{array}{l}\Phi=2 \mu \mathrm{m}, \quad 900 \\
\mathrm{~nm} \text { and } 400 \mathrm{~nm} \\
\rho_{c}=0.4-0.6 \\
\left.\mathrm{~g} / \mathrm{cm}^{3}\right) \\
\mathrm{R}=10 \text { weight } \%\end{array}$ & $\begin{array}{l}\mathrm{N}=10,40,70 \\
\mathrm{~N}, \\
\omega=300,600, \\
900 \mathrm{rpm} \\
\mathrm{L}=2,4,6 \mathrm{~km}\end{array}$ & $\begin{array}{l}\text { 1. The submicron sized particles are more effective } \\
\text { in improving the wear resistance than the } \\
\text { microsized particles. } \\
\text { 2. Load and filler content have } 75 \cdot 33 \% \text { and } 13.23 \% \\
\text { contribution on COF. } \\
\text { 3. Applied load is an important parameter for } \\
\text { specific wear rate. }\end{array}$ \\
\hline
\end{tabular}

$\Phi=$ particle diameter, $\rho_{c}=$ particle density, $\mathrm{R}=$ particle content

$\mathrm{L}=$ Sliding distance, $\mathrm{v}=$ speed, $\mathrm{N}=$ Normal load, $\omega=\mathrm{rpm}$ 
Table 2. Chemical, physical and sieve analysis details of cenospheres".

\begin{tabular}{|c|c|c|c|c|c|}
\hline \multicolumn{2}{|c|}{ Physical properties } & \multicolumn{2}{|c|}{ Chemical analysis } & \multicolumn{2}{|c|}{ Sieve analysis } \\
\hline $\begin{array}{l}\text { True particle } \\
\text { density }\end{array}$ & $750 \mathrm{~kg} / \mathrm{m}^{3}$ & $\mathrm{SiO}_{2}$ & $52-62 \%$ & $+30 \#(500 \mu \mathrm{m})$ & Nil \\
\hline Bulk density & $400-450 \mathrm{~kg} / \mathrm{m}^{3}$ & $\mathrm{Al}_{2} \mathrm{O}_{3}$ & $32-36 \%$ & $+60 \#(250 \mu \mathrm{m})$ & Nil \\
\hline Hardness (MOH) & $5-6$ & $\mathrm{CaO}$ & $0.1-0.5 \%$ & $+100 \#(150 \mu \mathrm{m})$ & Nil \\
\hline $\begin{array}{l}\text { Compressive } \\
\text { strength }\end{array}$ & $180-280 \mathrm{~kg} / \mathrm{m}^{3}$ & $\mathrm{Fe}_{2} \mathrm{O}_{3}$ & $1-3 \%$ & $+120 \#(125 \mu \mathrm{m})$ & Nil \\
\hline Shape & Spherical & $\mathrm{TiO}_{2}$ & $0.8-1.3 \%$ & $+150 \#(106 \mu \mathrm{m})$ & $0-10 \%$ \\
\hline Packing factor & $60-65 \%$ & $\mathrm{MgO}$ & $1-2.5 \%$ & $+240 \#(63 \mu \mathrm{m})$ & $70-95 \%$ \\
\hline Melting point & $1200-1300{ }^{\circ} \mathrm{C}$ & $\mathrm{Na}_{2} \mathrm{O}$ & $0.2-0.6 \%$ & $-240 \#$ & $0-30 \%$ \\
\hline $\mathrm{pH}$ in water & $6-7$ & $\mathrm{~K}_{2} \mathrm{O}$ & $1.2-3.2 \%$ & & \\
\hline Moisture & $0.5 \% \max$. & $\mathrm{CO}_{2}$ & $70 \%$ & & \\
\hline Loss on ignition & $2 \% \max$ & $\mathrm{N}_{2}$ & $30 \%$ & & \\
\hline $\begin{array}{l}\text { Sinkers } \\
\text { Oil absorption }\end{array}$ & $\begin{array}{c}5 \% \max . \\
16-18 \mathrm{~g} / 100 \mathrm{~g}\end{array}$ & & & & \\
\hline
\end{tabular}

*As provided by the supplier. 
Table 3. Process parameters and their levels.

\begin{tabular}{|l|c|c|c|}
\hline \multirow{2}{*}{\multicolumn{1}{|c|}{ Parameter }} & \multicolumn{3}{|c|}{ Level } \\
\cline { 2 - 4 } & $\mathbf{1}$ & $\mathbf{2}$ & $\mathbf{3}$ \\
\hline Sliding velocity (v), m/s & 0.5 & 1 & 1.5 \\
\hline Applied normal load (F), N & 10 & 30 & 50 \\
\hline Sliding distance (d), m & 1000 & 2000 & 3000 \\
\hline Filler content (R), weight\% & 20 & 40 & 60 \\
\hline
\end{tabular}


Table 4. Density and void fraction of epoxy/cenosphere syntactic foams.

\begin{tabular}{|c|c|c|c|}
\hline $\begin{array}{c}\text { Filler content } \\
(\text { weight } \%)\end{array}$ & $\begin{array}{c}\text { Measured density }\left(\boldsymbol{\rho}_{\mathbf{c e}}\right) \\
\left(\mathbf{g} / \mathbf{c m}^{\mathbf{3}}\right)\end{array}$ & $\begin{array}{c}\text { Theoretical density }\left(\boldsymbol{\rho}_{\mathrm{ct}}\right) \\
\left(\mathbf{g} / \mathbf{c m}^{\mathbf{3}}\right)\end{array}$ & $\begin{array}{c}\text { Matrix porosity } \\
(\mathbf{v o l .} \mathbf{\%})\end{array}$ \\
\hline 20 & $1.039 \pm 0.005$ & 1.071 & 2.96 \\
\hline 40 & $0.950 \pm 0.007$ & 1.013 & 6.17 \\
\hline 60 & $0.874 \pm 0.010$ & 0.973 & 10.19 \\
\hline
\end{tabular}


Table 5. Experimentally measured wear rate, specific wear rate and coefficient of friction for different force, sliding distance and cenosphere content, at a velocity of $0.5 \mathrm{~m} / \mathrm{s}$.

\begin{tabular}{|c|c|c|c|c|c|c|}
\hline \multicolumn{4}{|c|}{ Process parameter settings } & \multicolumn{3}{|c|}{ Outcome } \\
\hline $\begin{array}{c}\mathbf{v} \\
(\mathbf{m} / \mathbf{s})\end{array}$ & $\begin{array}{c}\mathbf{F} \\
(\mathbf{N})\end{array}$ & $\begin{array}{c}\mathbf{d} \\
(\mathbf{m})\end{array}$ & \begin{tabular}{|c|c|}
$\mathbf{R}$ \\
(weight\%)
\end{tabular} & $\begin{array}{c}\mathbf{w}_{\mathrm{t}} \\
\left(\mathrm{mm}^{3} / \mathbf{k m}\right) \\
\end{array}$ & $\begin{array}{c}\mathbf{w}_{\mathbf{s}} \\
\left(\mathbf{m m}^{3} / \mathbf{N}-\mathbf{k m}\right) \\
\end{array}$ & $\boldsymbol{\mu}$ \\
\hline \multirow{27}{*}{0.5} & \multirow{9}{*}{10} & \multirow{3}{*}{1000} & 20 & 6.44 & 0.6565 & 0.393 \\
\hline & & & 40 & 4.86 & 0.4954 & 0.459 \\
\hline & & & 60 & 3.42 & 0.3486 & 0.478 \\
\hline & & \multirow{3}{*}{2000} & 20 & 4.31 & 0.4394 & 0.462 \\
\hline & & & 40 & 3.87 & 0.3945 & 0.509 \\
\hline & & & 60 & 2.66 & 0.2715 & 0.644 \\
\hline & & \multirow{3}{*}{3000} & 20 & 3.76 & 0.3833 & 0.479 \\
\hline & & & 40 & 2.89 & 0.2946 & 0.498 \\
\hline & & & 60 & 2.27 & 0.2314 & 0.482 \\
\hline & \multirow{9}{*}{30} & \multirow{3}{*}{1000} & 20 & 6.66 & 0.2263 & 0.490 \\
\hline & & & 40 & 5.45 & 0.1852 & 0.500 \\
\hline & & & 60 & 3.82 & 0.1298 & 0.513 \\
\hline & & \multirow{3}{*}{2000} & 20 & 5.43 & 0.1845 & 0.488 \\
\hline & & & 40 & 3.49 & 0.1186 & 0.568 \\
\hline & & & 60 & 2.35 & 0.0799 & 0.531 \\
\hline & & \multirow{3}{*}{3000} & 20 & 5.27 & 0.1791 & 0.454 \\
\hline & & & 40 & 3.26 & 0.1108 & 0.474 \\
\hline & & & 60 & 3.14 & 0.1067 & 0.632 \\
\hline & \multirow{9}{*}{50} & \multirow{3}{*}{1000} & 20 & 7.10 & 0.1448 & 0.600 \\
\hline & & & 40 & 6.76 & 0.1378 & 0.516 \\
\hline & & & 60 & 5.48 & 0.1117 & 0.492 \\
\hline & & \multirow{3}{*}{2000} & 20 & 6.12 & 0.1248 & 0.471 \\
\hline & & & 40 & 5.90 & 0.1203 & 0.483 \\
\hline & & & 60 & 5.00 & 0.1019 & 0.579 \\
\hline & & \multirow{3}{*}{3000} & 20 & 5.95 & 0.1213 & 0.316 \\
\hline & & & 40 & 4.13 & 0.0842 & 0.529 \\
\hline & & & 60 & 3.74 & 0.0763 & 0.232 \\
\hline
\end{tabular}


Table 6. Experimentally measured wear rate, specific wear rate and coefficient of friction for different force, sliding distance and cenosphere content, at a velocity of $1.0 \mathrm{~m} / \mathrm{s}$.

\begin{tabular}{|c|c|c|c|c|c|c|}
\hline \multicolumn{4}{|c|}{ Process parameter settings } & \multicolumn{3}{|c|}{ Outcome } \\
\hline $\begin{array}{c}\mathbf{v} \\
(\mathbf{m} / \mathbf{s})\end{array}$ & $\begin{array}{c}\mathbf{F} \\
(\mathbf{N})\end{array}$ & $\begin{array}{c}\text { d } \\
(\mathbf{m})\end{array}$ & $\begin{array}{c}\mathrm{R} \\
\text { (weight\%) }\end{array}$ & $\mathbf{w}_{\mathrm{t}}\left(\mathrm{mm}^{3} / \mathbf{k m}\right)$ & $\begin{array}{c}\mathbf{W}_{\mathrm{s}} \\
\left(\mathbf{m m}^{\mathbf{3}} / \mathbf{N}-\mathbf{k m}\right) \\
\end{array}$ & $\mu$ \\
\hline \multirow{28}{*}{1.0} & \multirow{9}{*}{10} & \multirow{3}{*}{1000} & 20 & 4.21 & 0.4292 & 0.367 \\
\hline & & & 40 & 4.60 & 0.4689 & 0.412 \\
\hline & & & 60 & 2.32 & 0.2365 & 0.255 \\
\hline & & \multirow{3}{*}{2000} & 20 & 3.03 & 0.3089 & 0.461 \\
\hline & & & 40 & 3.80 & 0.3874 & 0.429 \\
\hline & & & 60 & 2.19 & 0.2232 & 0.172 \\
\hline & & \multirow{3}{*}{3000} & 20 & 2.71 & 0.2763 & 0.494 \\
\hline & & & 40 & 2.31 & 0.2355 & 0.402 \\
\hline & & & 60 & 1.29 & 0.1315 & 0.584 \\
\hline & \multirow{10}{*}{30} & 1000 & 0 & NA & $0.22 *$ & NA \\
\hline & & \multirow{3}{*}{1000} & 20 & 5.88 & 0.1998 & 0.365 \\
\hline & & & 40 & 5.30 & 0.1801 & 0.422 \\
\hline & & & 60 & 2.46 & 0.0836 & 0.376 \\
\hline & & \multirow{3}{*}{2000} & 20 & 3.90 & 0.1325 & 0.399 \\
\hline & & & 40 & 4.17 & 0.1417 & 0.394 \\
\hline & & & 60 & 2.49 & 0.0845 & 0.509 \\
\hline & & \multirow{3}{*}{3000} & 20 & 4.20 & 0.1427 & 0.363 \\
\hline & & & 40 & 3.51 & 0.1193 & 0.434 \\
\hline & & & 60 & 1.36 & 0.0462 & 0.490 \\
\hline & \multirow{9}{*}{50} & \multirow{3}{*}{1000} & 20 & 6.13 & 0.1250 & 0.483 \\
\hline & & & 40 & 4.58 & 0.0934 & 0.502 \\
\hline & & & 60 & 4.87 & 0.0993 & 0.277 \\
\hline & & \multirow{3}{*}{2000} & 20 & 5.63 & 0.1148 & 0.506 \\
\hline & & & 40 & 4.48 & 0.0913 & 0.386 \\
\hline & & & 60 & 3.88 & 0.0791 & 0.396 \\
\hline & & \multirow{3}{*}{3000} & 20 & 4.80 & 0.0979 & 0.393 \\
\hline & & & 40 & 5.26 & 0.1072 & 0.384 \\
\hline & & & 60 & 3.02 & 0.0616 & 0.485 \\
\hline
\end{tabular}

* Data obtained from reference [34]. 
Table 7. Experimentally measured wear rate, specific wear rate and coefficient of friction for different force, sliding distance and cenosphere content, at a velocity of $1.5 \mathrm{~m} / \mathrm{s}$.

\begin{tabular}{|c|c|c|c|c|c|c|}
\hline \multicolumn{4}{|c|}{ Process parameter settings } & \multicolumn{3}{|c|}{ Outcome } \\
\hline $\begin{array}{c}\mathbf{v} \\
(\mathbf{m} / \mathbf{s})\end{array}$ & $\begin{array}{c}\mathbf{F} \\
(\mathbf{N})\end{array}$ & $\begin{array}{c}\text { d } \\
(\mathbf{m})\end{array}$ & $\begin{array}{c}\mathbf{R} \\
\text { (weight\%) }\end{array}$ & $\begin{array}{c}\mathbf{w}_{\mathrm{t}} \\
\left(\mathrm{mm}^{3} / \mathbf{k m}\right)\end{array}$ & $\begin{array}{c}\mathrm{W}_{\mathrm{s}} \\
\left(\mathrm{mm}^{3} / \mathrm{N}-\mathrm{km}\right)\end{array}$ & $\mu$ \\
\hline \multirow{27}{*}{1.5} & \multirow{9}{*}{10} & \multirow{3}{*}{1000} & 20 & 3.88 & 0.3955 & 0.390 \\
\hline & & & 40 & 3.60 & 0.3670 & 0.365 \\
\hline & & & 60 & 1.91 & 0.1949 & 0.312 \\
\hline & & \multirow{3}{*}{2000} & 20 & 2.82 & 0.2875 & 0.436 \\
\hline & & & 40 & 3.32 & 0.3384 & 0.343 \\
\hline & & & 60 & 1.50 & 0.1527 & 0.458 \\
\hline & & \multirow{3}{*}{3000} & 20 & 2.20 & 0.2243 & 0.423 \\
\hline & & & 40 & 1.49 & 0.1519 & 0.329 \\
\hline & & & 60 & 1.10 & 0.1121 & 0.418 \\
\hline & \multirow{9}{*}{30} & \multirow{3}{*}{1000} & 20 & 4.11 & 0.1397 & 0.395 \\
\hline & & & 40 & 3.86 & 0.1312 & 0.369 \\
\hline & & & 60 & 2.23 & 0.0758 & 0.301 \\
\hline & & \multirow{3}{*}{2000} & 20 & 3.74 & 0.1271 & 0.455 \\
\hline & & & 40 & 3.52 & 0.1196 & 0.372 \\
\hline & & & 60 & 1.80 & 0.0612 & 0.616 \\
\hline & & \multirow{3}{*}{3000} & 20 & 3.50 & 0.1189 & 0.477 \\
\hline & & & 40 & 3.30 & 0.1121 & 0.349 \\
\hline & & & 60 & 2.86 & 0.0972 & 0.423 \\
\hline & \multirow{9}{*}{50} & \multirow{3}{*}{1000} & 20 & 4.64 & 0.0946 & 0.307 \\
\hline & & & 40 & 4.36 & 0.0889 & 0.274 \\
\hline & & & 60 & 2.73 & 0.0557 & 0.592 \\
\hline & & \multirow{3}{*}{2000} & 20 & 4.27 & 0.0871 & 0.386 \\
\hline & & & 40 & 3.89 & 0.0793 & 0.356 \\
\hline & & & 60 & 2.19 & 0.0447 & 0.517 \\
\hline & & \multirow{3}{*}{3000} & 20 & 7.30 & 0.1488 & 0.420 \\
\hline & & & 40 & 4.12 & 0.0840 & 0.431 \\
\hline & & & 60 & 3.51 & 0.0716 & 0.456 \\
\hline
\end{tabular}


Table 8. Summary of ANOVA results and coefficient of determination (CoD) values for the regression model.

\begin{tabular}{|l|c|c|c|c|c|c|c|c|}
\hline \multirow{2}{*}{$\begin{array}{l}\text { Para- } \\
\text { meter }\end{array}$} & \multicolumn{2}{|c|}{ Sum of squares } & \multicolumn{2}{c|}{ Degrees of freedom } & \multicolumn{2}{c|}{ Mean square } & \multirow{2}{*}{ F-ratio } & \multirow{2}{*}{ CoD } \\
\cline { 2 - 9 } & Regression & Residual & Regression & Residual & Regression & Residual & & \\
\hline $\mathrm{w}_{\mathrm{t}}$ & 144.279 & 23.001 & 14 & 66 & 10.306 & 0.49 & $29.58^{*}$ & 0.862 \\
\hline $\mathrm{w}_{\mathrm{s}}$ & 1.133 & 0.0761 & 14 & 66 & 0.081 & 0.0011 & $70.17^{*}$ & 0.937 \\
\hline$\mu$ & 0.2271 & 0.5589 & 14 & 66 & 0.0162 & 0.0085 & $1.92^{*} *$ & 0.289 \\
\hline
\end{tabular}

*Significance at $99 \%$ confidence interval

**Significance at $95 \%$ confidence interval 
Table 9. Two-way interaction parameters used in the study.

\begin{tabular}{|c|c|c|}
\hline \multicolumn{2}{|c|}{ Interaction } & $\begin{array}{c}\text { Property } \\
\text { investigated }\end{array}$ \\
\hline Parameter 1 & Parameter 2 & \\
Sliding velocity & Normal load & \multirow{2}{*}{$\mathrm{W}_{\mathrm{t}}$} \\
& Sliding distance & $\mathrm{w}_{\mathrm{s}}$ \\
& Filler content & $\mu$ \\
\hline \multirow{2}{*}{ Sliding distance } & Normal load & \\
\hline Filler content & Filler content \\
\hline
\end{tabular}




\section{Figure captions}

Figure 1. SEM images of two different syntactic foam specimens containing 60 weight $\%$ of cenospheres at (a) lower and (b) higher magnifications. The particles are observed to be uniformly dispersed in these micrographs.

Figure 2. A representative set of graphs obtained from the wear test: (a) height loss and (b) frictional force with respect to time of wear.

Figure 3. Wear mechanism in syntactic foams: (a) some cut cenospheres are present on the initial wear surface, which tend to fill with debris of resin and cenosphere walls, (b) continued wear opens up new cenosphere cavities for additional debris accumulation and (c) after sufficient wear, the debris accumulated in the cavity are released to the surface, which act a lubricant.

Figure 4. SEM images of the wear surface of a syntactic foam at three different magnifications progressively increasing from (a) - (c). Arrows in (a) mark the steps related to shear deformation and the debris is observed in (b)-(c). The syntactic foam corresponds to $\mathrm{v}=1.5 \mathrm{~m} / \mathrm{s}, \mathrm{F}=50 \mathrm{~N}, \mathrm{~d}$ $=2000 \mathrm{~m}$ and $\mathrm{R}=60$ weight $\%$.

Figure 5. Variation of the wear rate with respect to individual parameters utilized in the study estimated by the model, (a) force and sliding velocity and (b) sliding distance and filler content.

Figure 6. Variation of the specific wear rate with respect to individual parameters utilized in the study estimated by the model, (a) force and sliding velocity and (b) sliding distance and filler content.

Figure 7. Variation of the coefficient of friction with respect to individual parameters utilized in the study estimated by the model, (a) force and sliding velocity and (b) sliding distance and filler content.

Figure 8. Model predictions for wear rate with respect to sliding velocity for different (a) normal loads, (b) sliding distances and (c) filler percentage. (d) Wear rate with respect to filler content at different normal loads. Wear rate with respect to sliding distance at different (e) normal loads and (f) filler contents.

Figure 9. Model predictions for specific wear rate with sliding velocity for different (a) normal loads, (b) sliding distances and (c) filler percentage. (d) Specific wear rate with respect to filler content at different normal loads. Specific wear rate with respect to sliding distance at different (e) normal loads and (f) filler contents.

Figure 10. Model predictions for coefficient of friction with sliding velocity for different (a) normal loads, (b) sliding distances and (c) filler percentage. (d) Coefficient of friction with respect to filler content at different normal loads. Coefficient of friction with respect to sliding distance at different (e) normal loads and (f) filler contents.

Figure 11. Normal probability plot of residuals for (a) wear rate, (b) specific wear rate and (c) coefficient of friction.

Figure 12. Comparison between measured and predicted values for (a) wear rate, (b) specific wear rate and (c) coefficient of friction. 


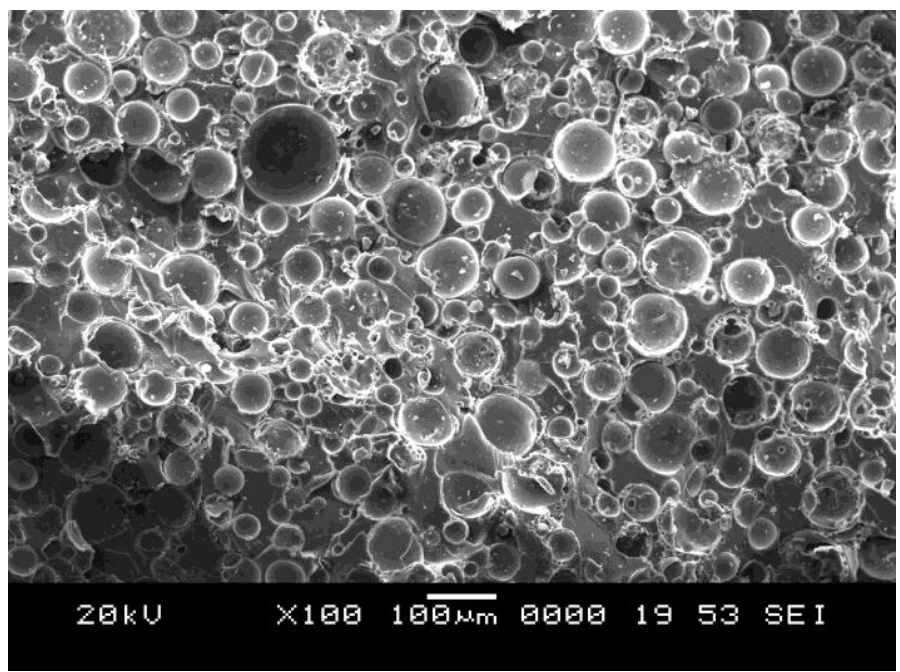

(a)

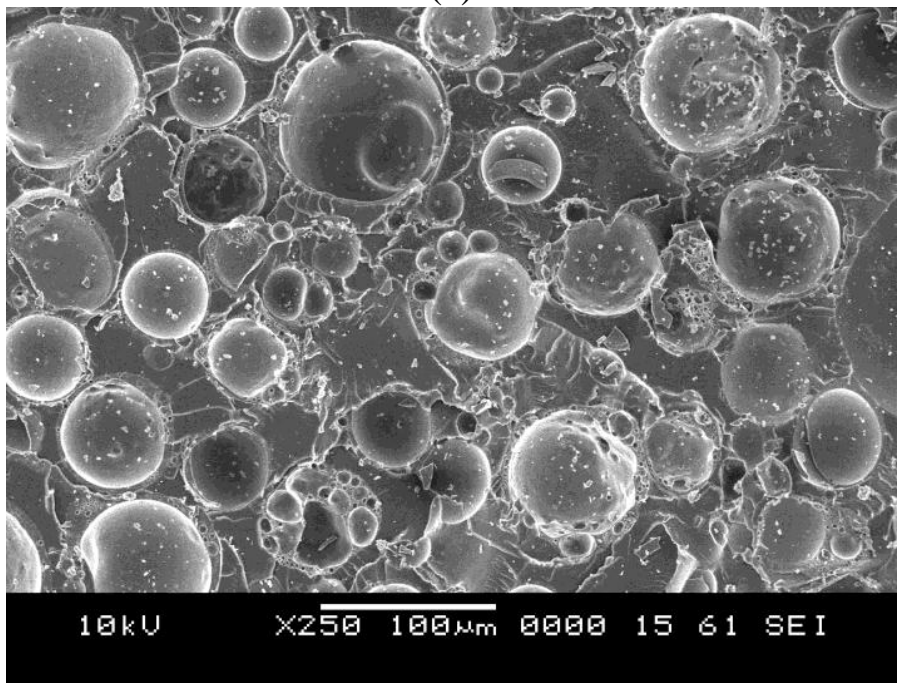

(b)

Figure 1. SEM images of two different syntactic foam specimens containing 60 weight $\%$ of cenospheres at (a) lower and (b) higher magnifications. The particles are observed to be uniformly dispersed in these micrographs. 


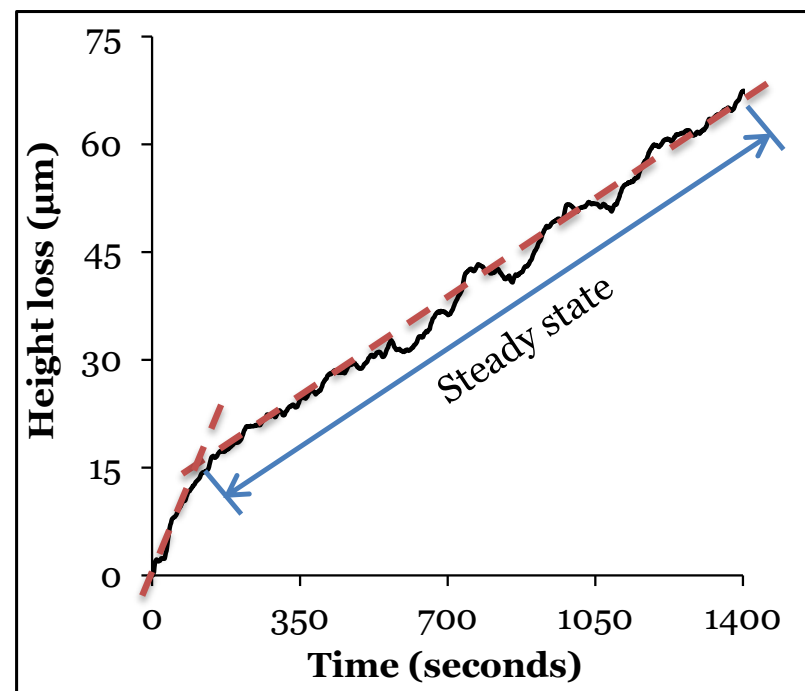

(a)

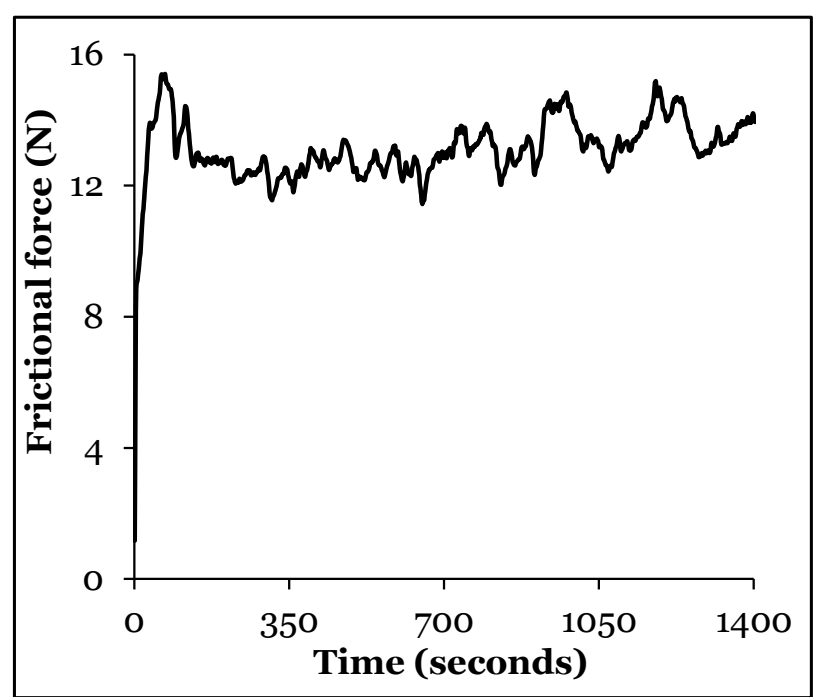

(b)

Figure 2. A representative set of graphs obtained from the wear test: (a) height loss and (b) frictional force with respect to time of wear. 


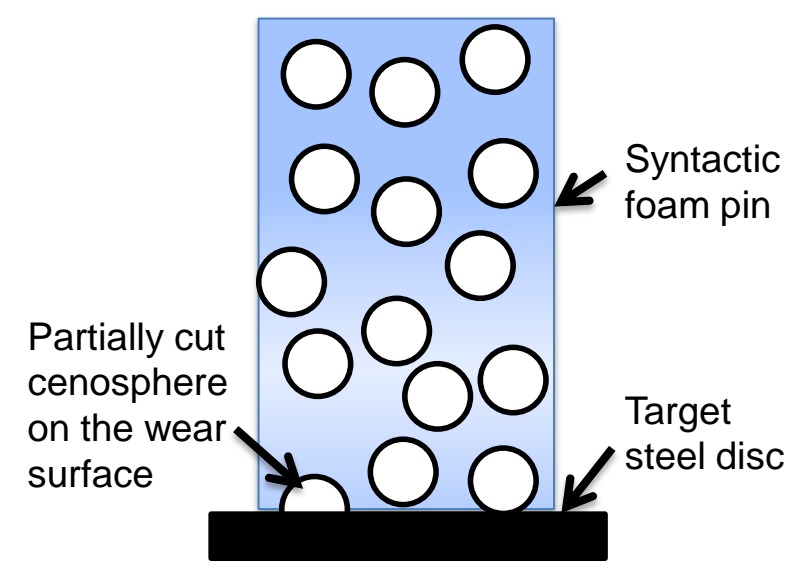

(a)

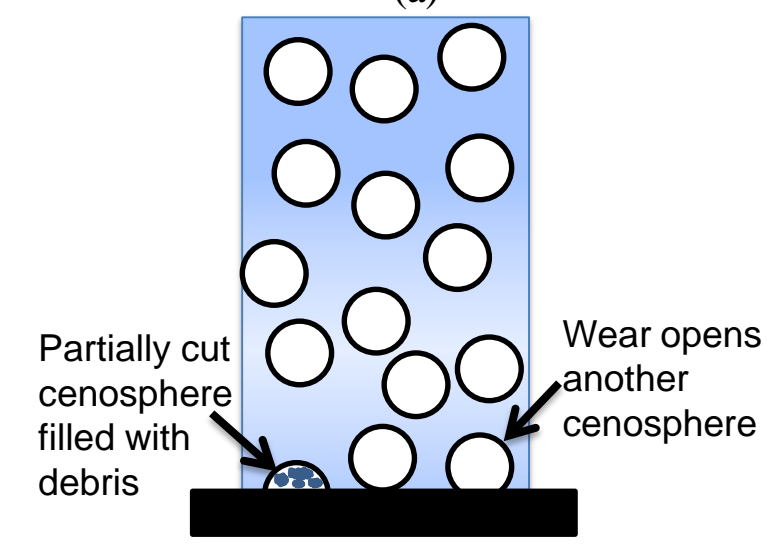

(b)

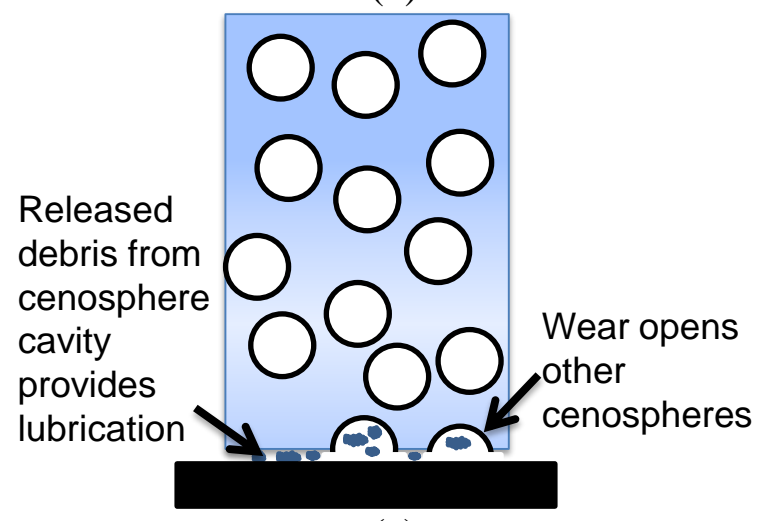

(c)

Figure 3. Wear mechanism in syntactic foams: (a) some cut cenospheres are present on the initial wear surface, which tend to fill with debris of resin and cenosphere walls, (b) continued wear opens up new cenosphere cavities for additional debris accumulation and (c) after sufficient wear, the debris accumulated in the cavity are released to the surface, which act a lubricant. 


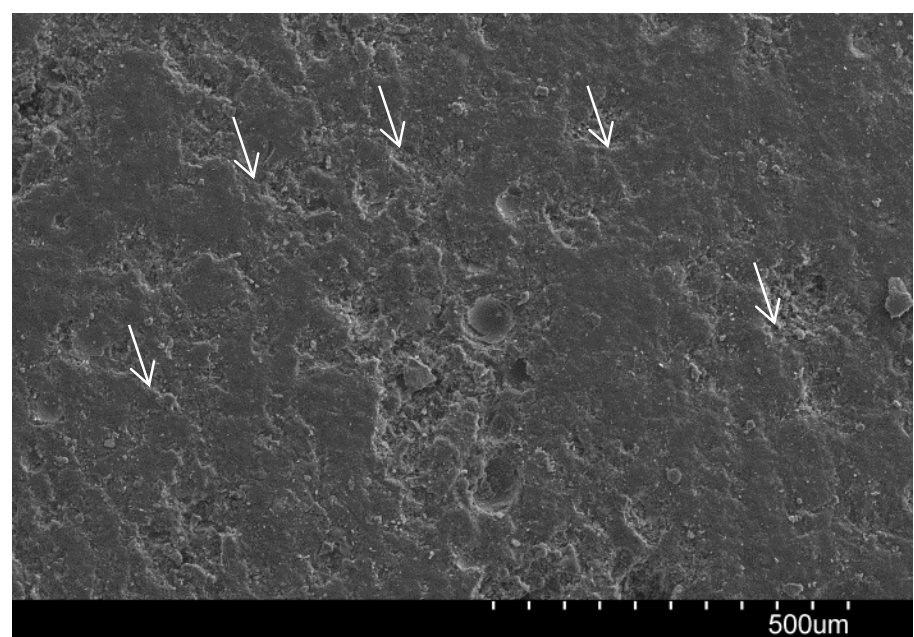

(a)

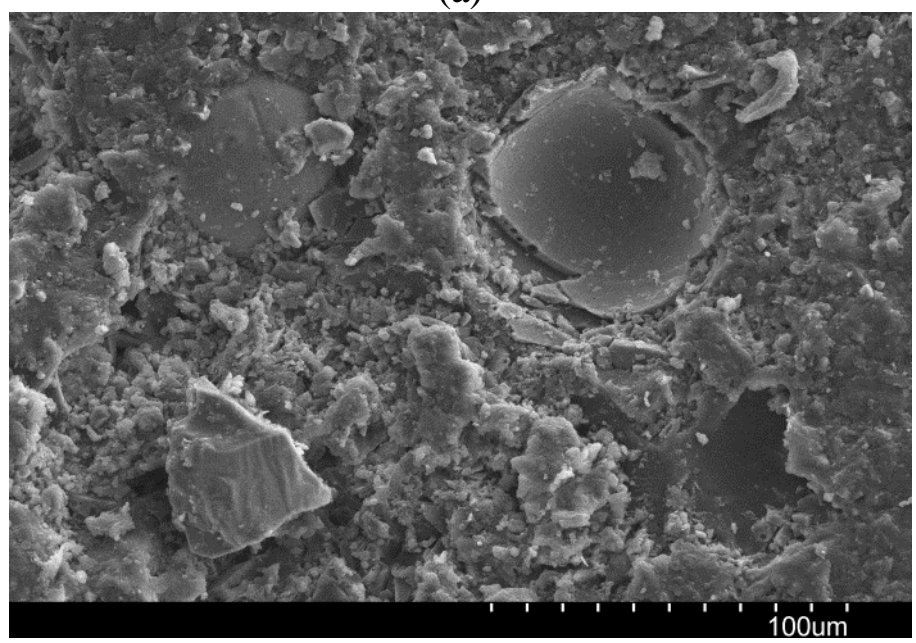

(b)



(c)

Figure 4. SEM images of the wear surface of a syntactic foam at three different magnifications progressively increasing from (a) - (c). Arrows in (a) mark the steps related to shear deformation and the debris is observed in (b)-(c). The syntactic foam corresponds to $\mathrm{v}=1.5 \mathrm{~m} / \mathrm{s}, \mathrm{F}=50 \mathrm{~N}, \mathrm{~d}=$ $2000 \mathrm{~m}$ and $\mathrm{R}=\mathbf{6 0}$ weight $\%$. 


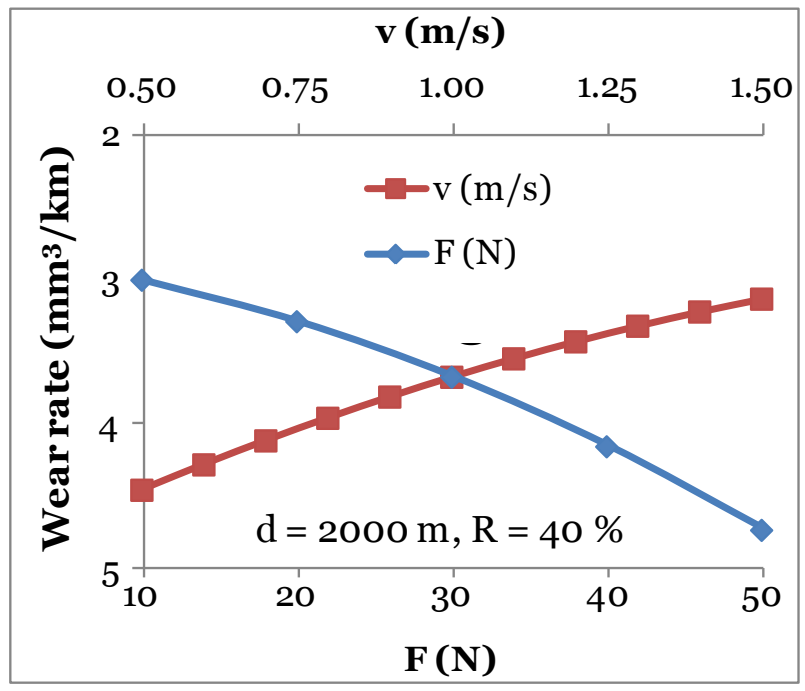

(a)

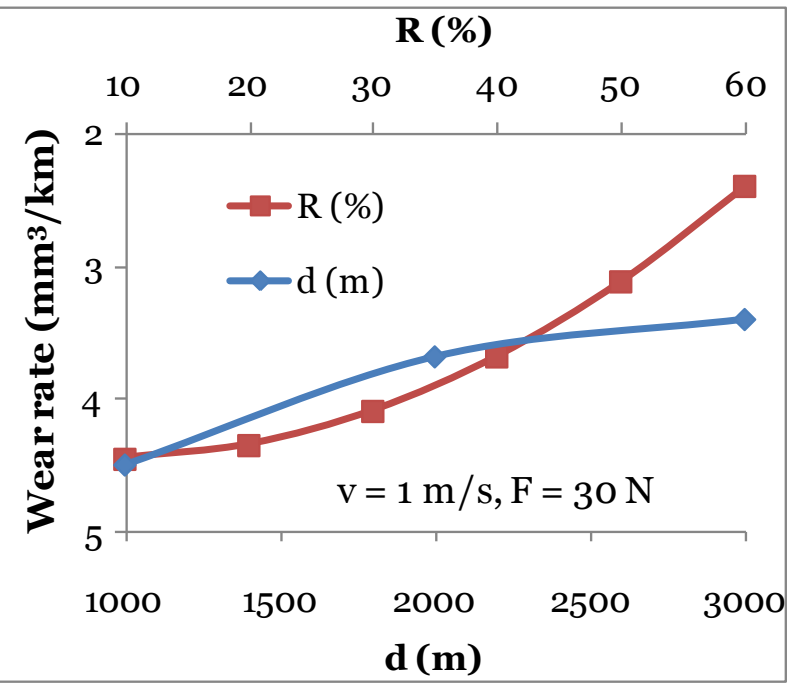

(b)

Figure 5. Variation of the wear rate with respect to individual parameters utilized in the study estimated by the model, (a) force and sliding velocity and (b) sliding distance and filler content. 


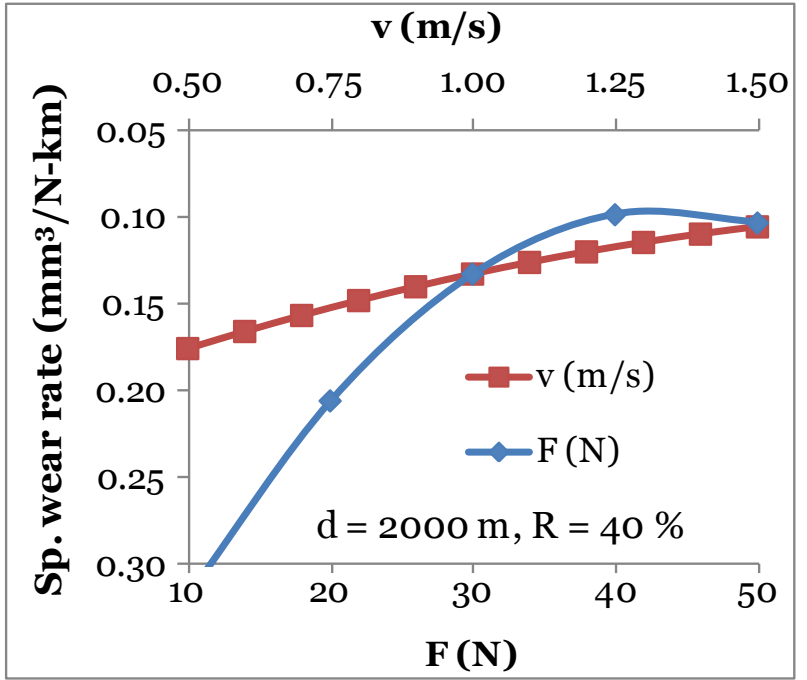

(a)

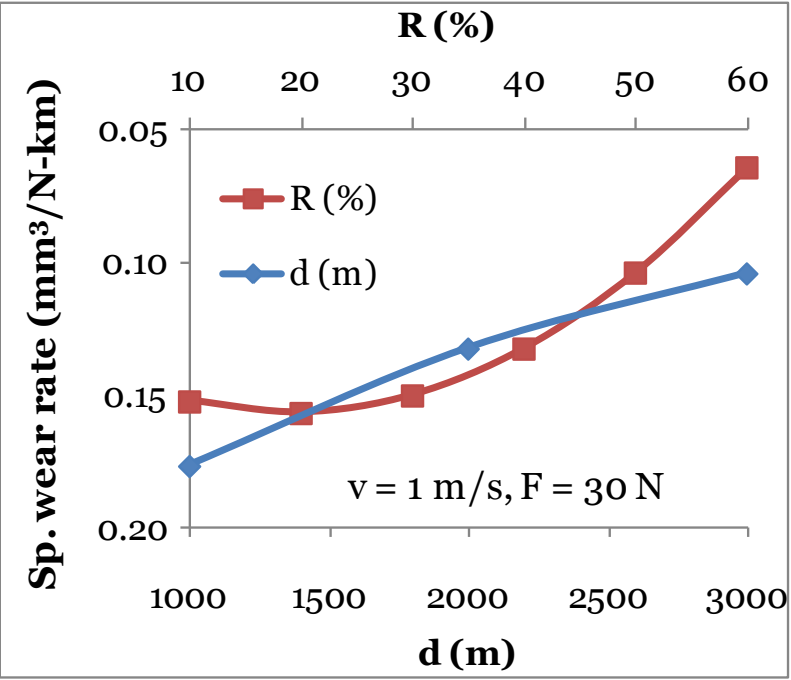

(b)

Figure 6. Variation of the specific wear rate with respect to individual parameters utilized in the study estimated by the model, (a) force and sliding velocity and (b) sliding distance and filler content. 


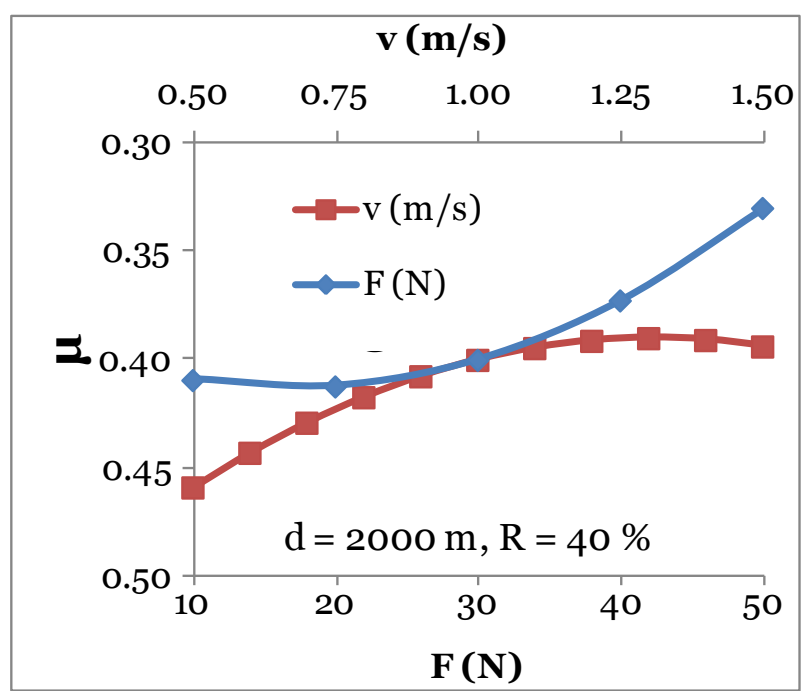

(a)

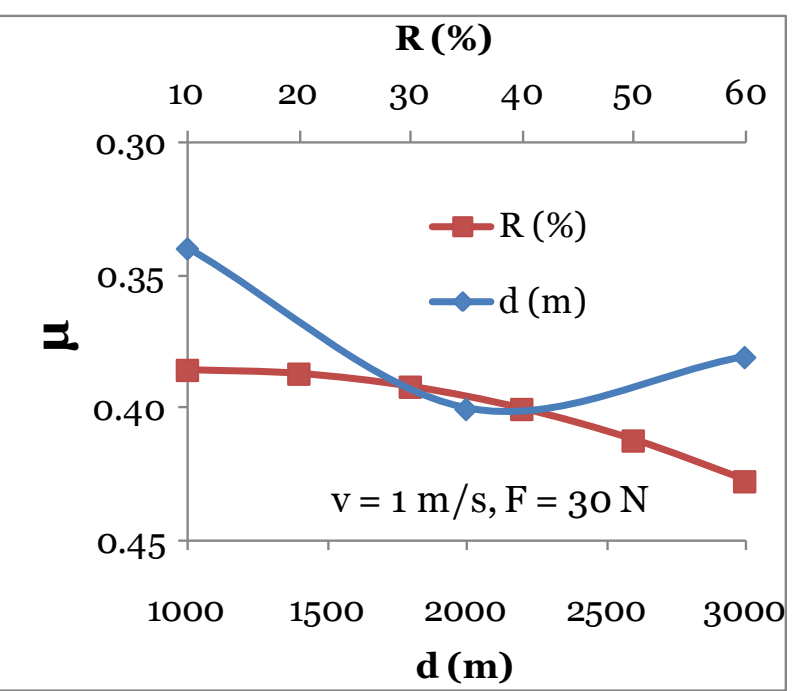

(b)

Figure 7. Variation of the coefficient of friction with respect to individual parameters utilized in the study estimated by the model, (a) force and sliding velocity and (b) sliding distance and filler content. 


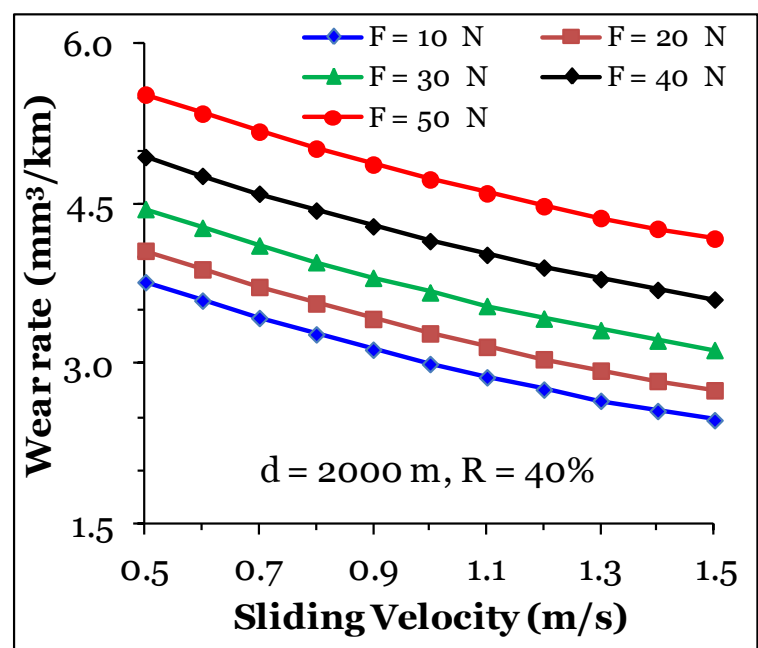

(a)

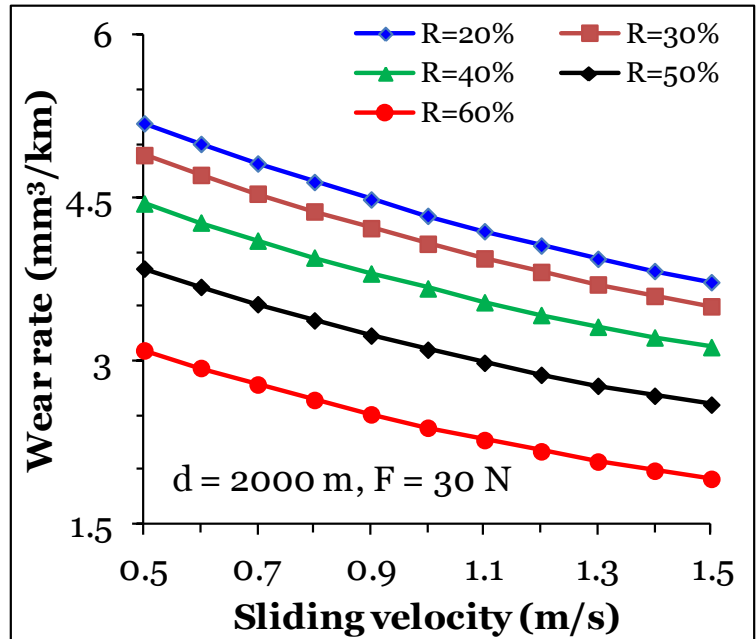

(c)

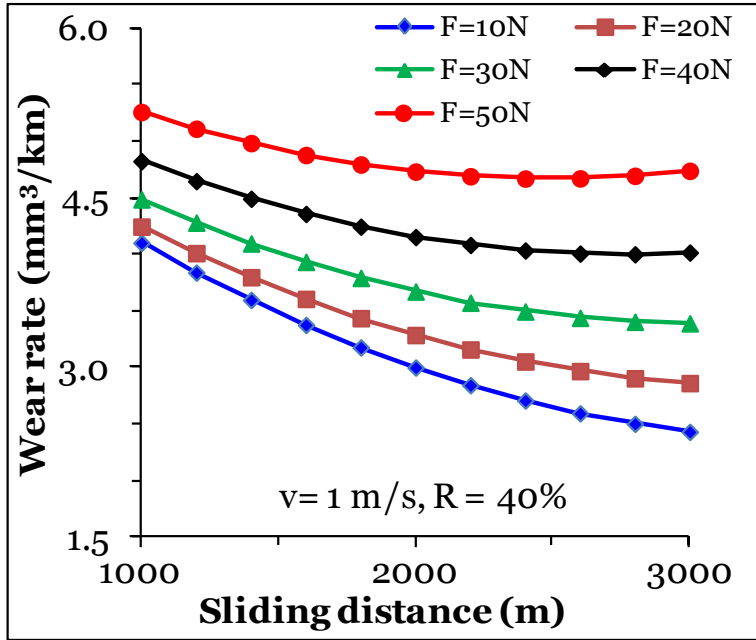

(e)

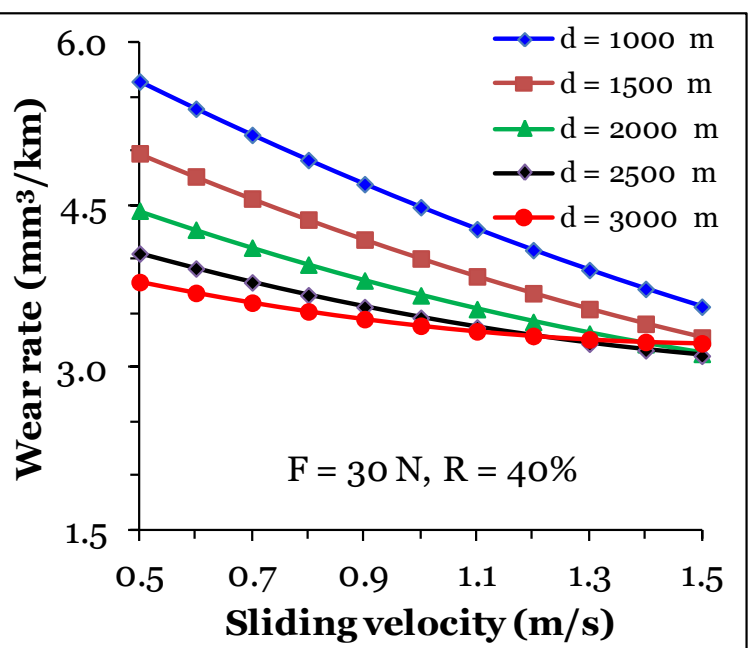

(b)

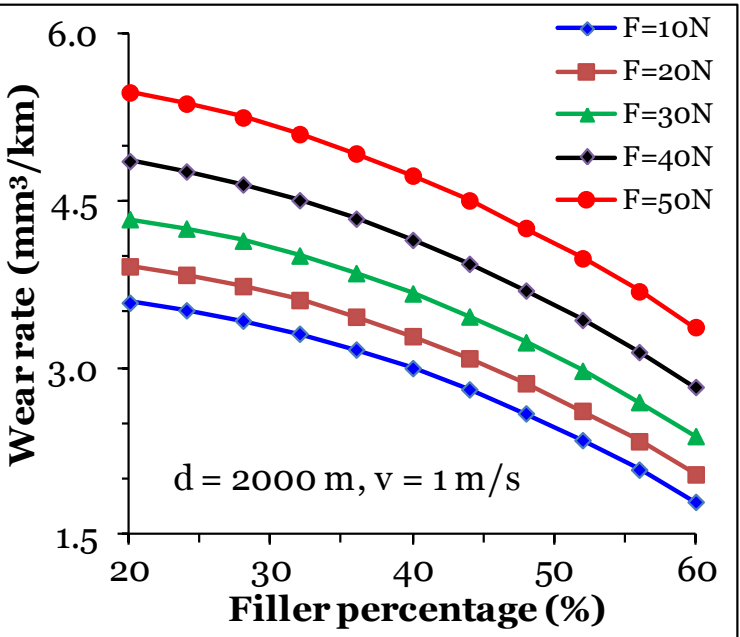

(d)

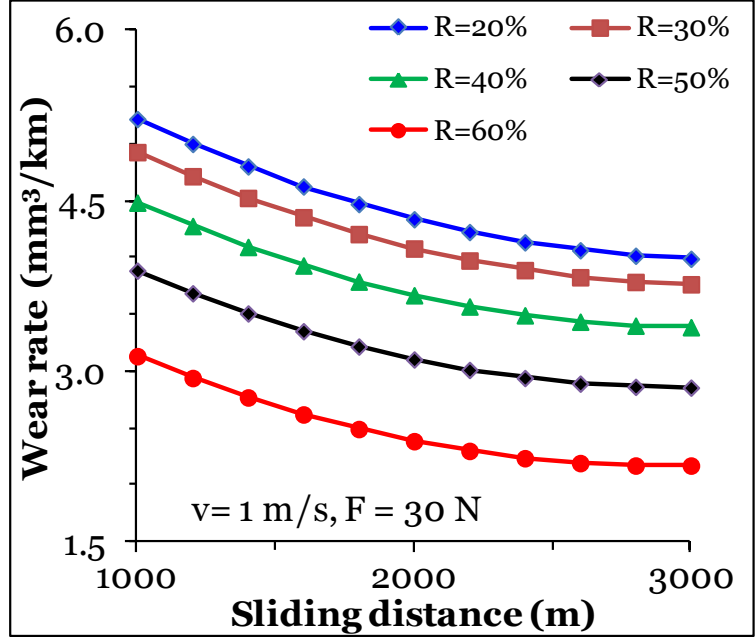

(f)

Figure 8. Model predictions for wear rate with respect to sliding velocity for different (a) normal loads, (b) sliding distances and (c) filler percentage. (d) Wear rate with respect to filler content at different normal loads. Wear rate with respect to sliding distance at different (e) normal loads and (f) filler contents. 


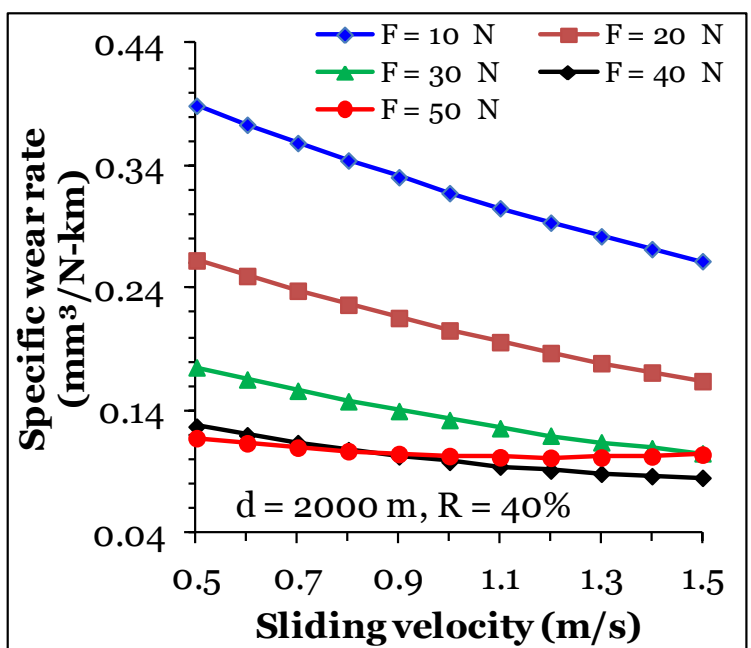

(a)

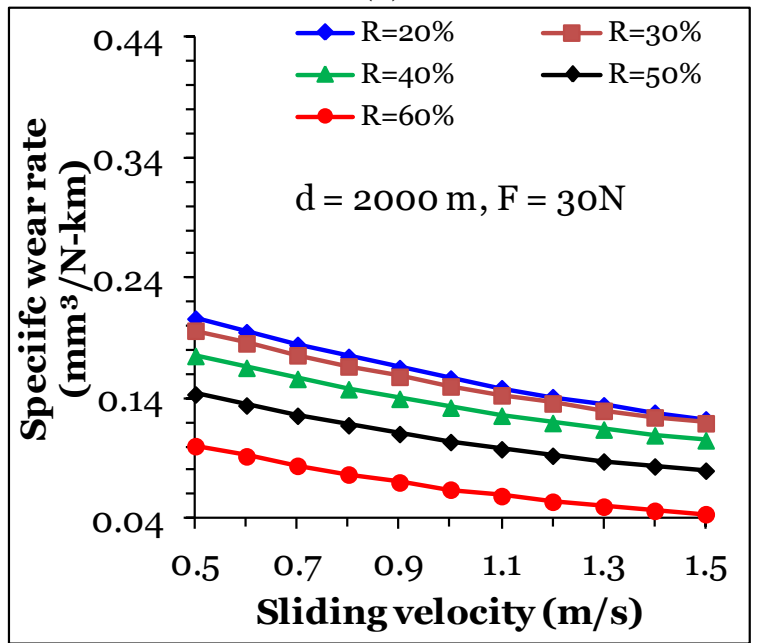

(c)

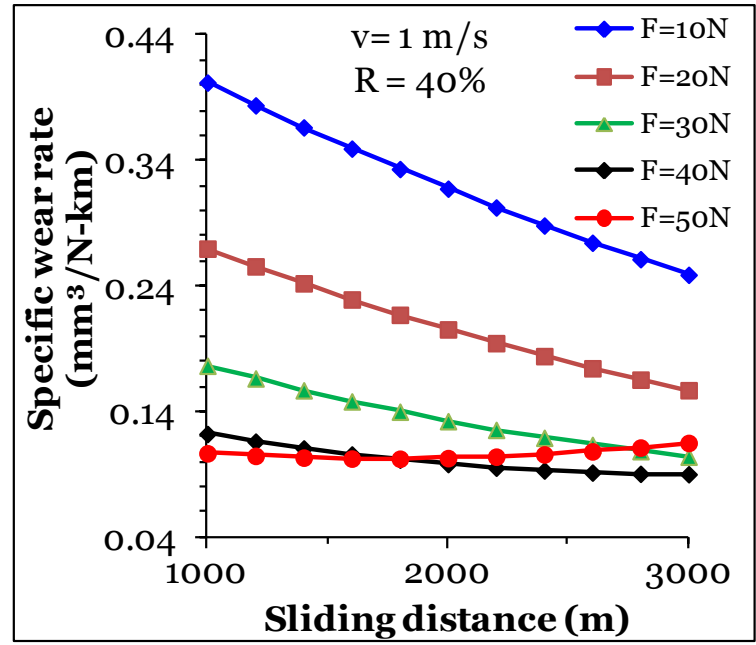

(e)

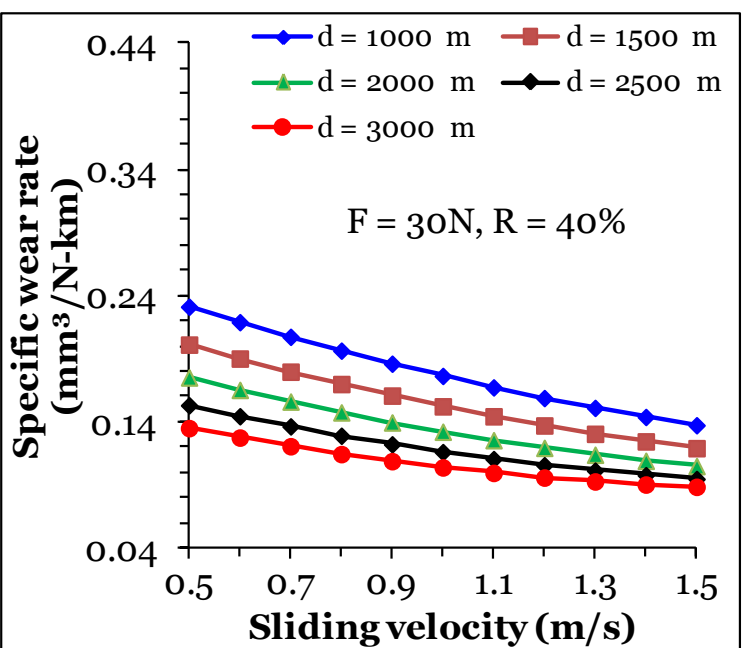

(b)

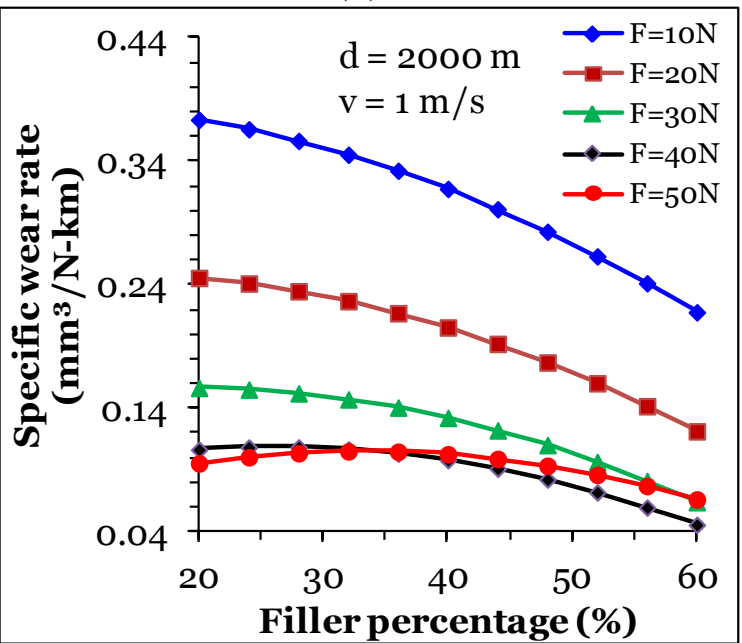

(d)

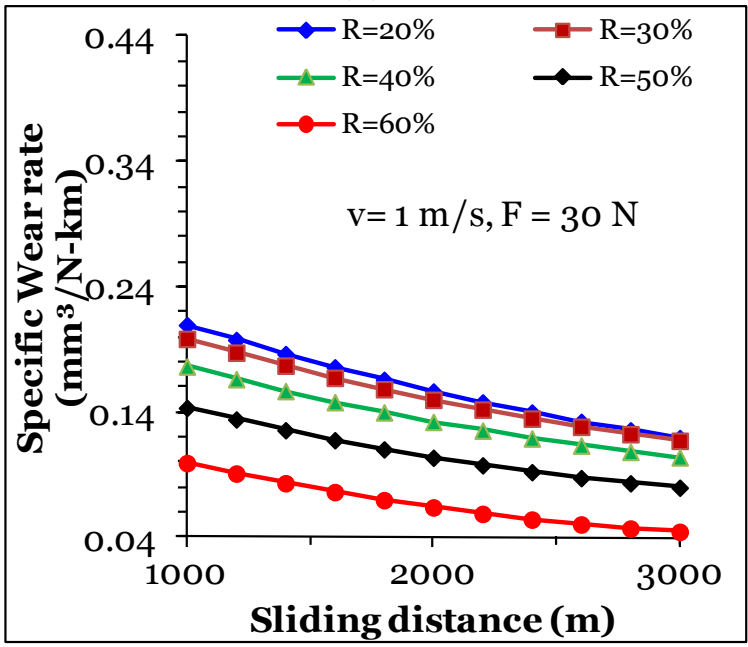

(f)

Figure 9. Model predictions for specific wear rate with sliding velocity for different (a) normal loads, (b) sliding distances and (c) filler percentage. (d) Specific wear rate with respect to filler content at different normal loads. Specific wear rate with respect to sliding distance at different (e) normal loads and (f) filler contents. 


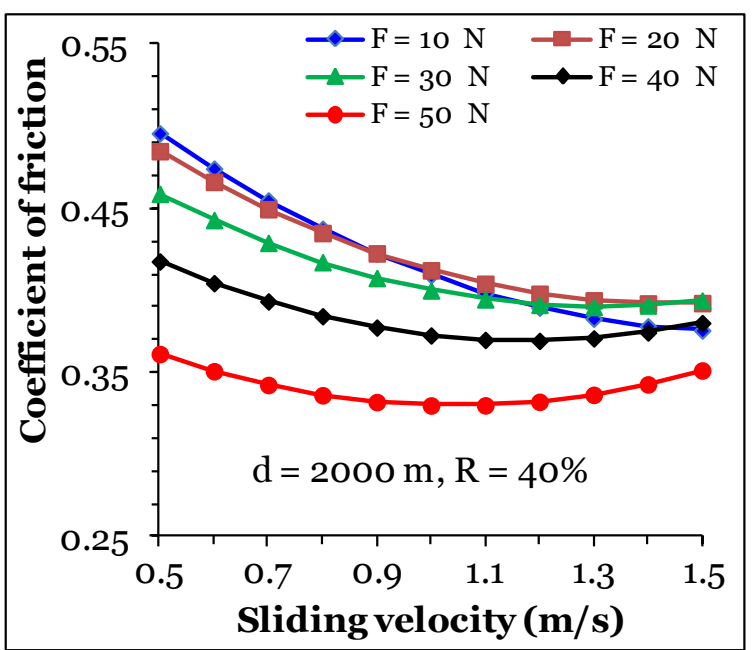

(a)

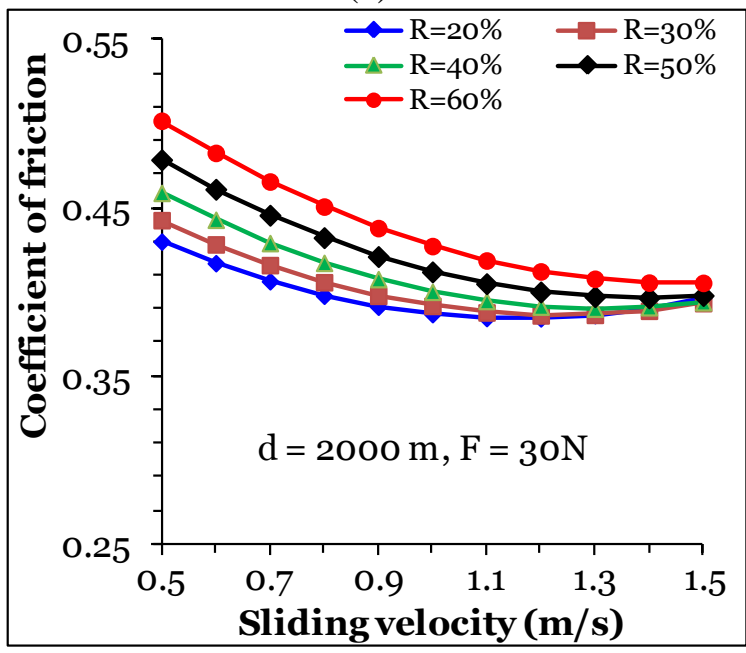

(c)

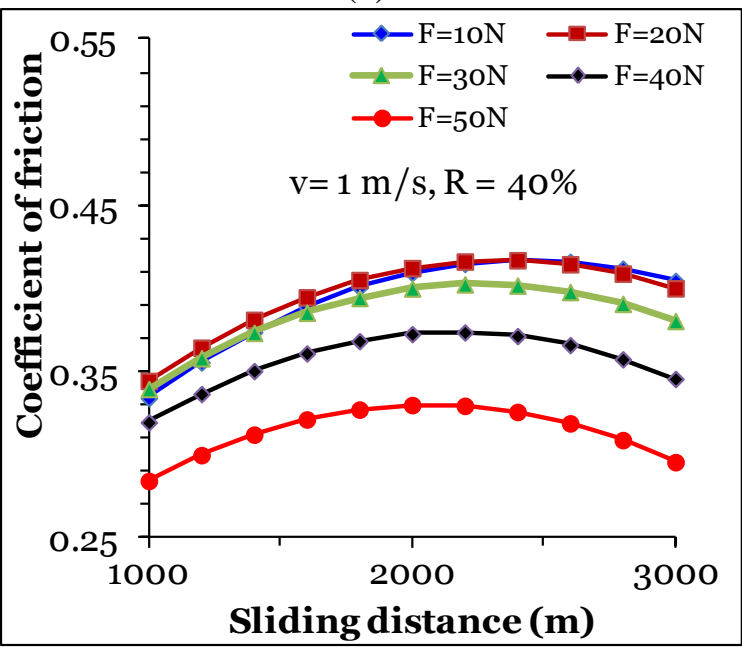

(e)

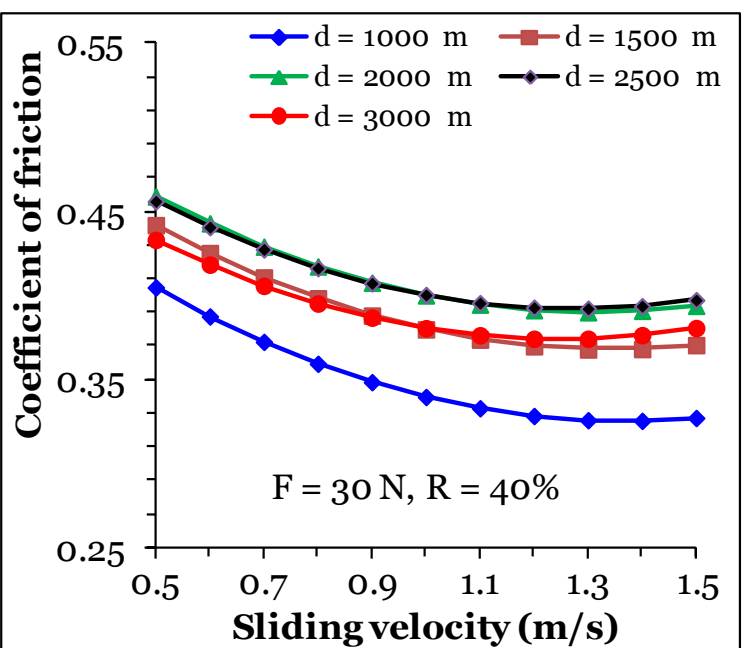

(b)

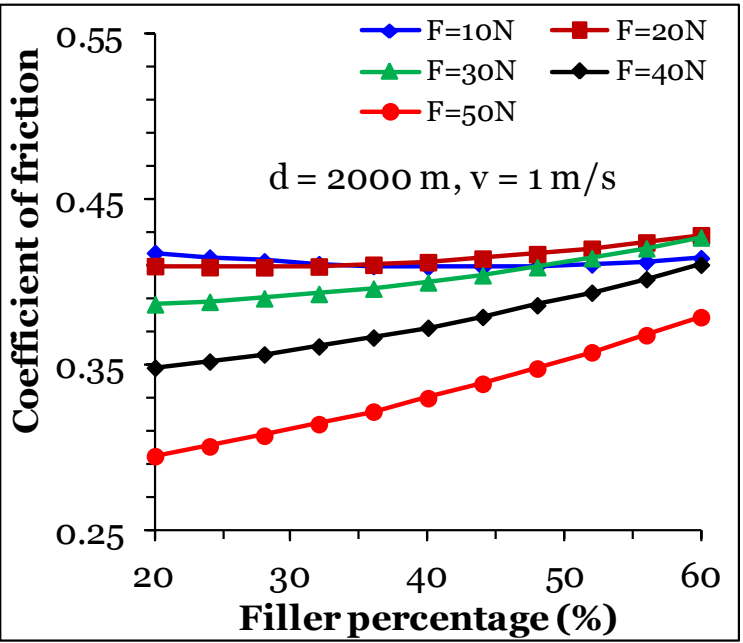

(d)

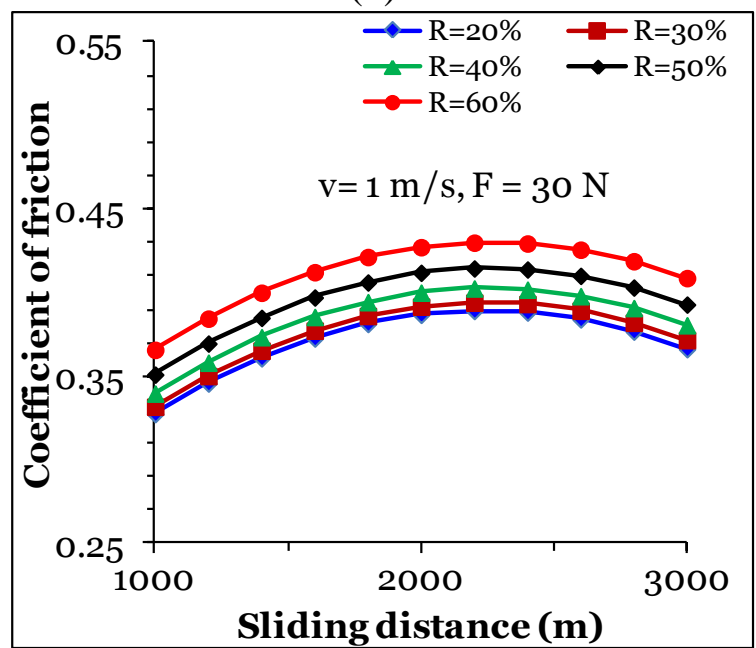

(f)

Figure 10. Model predictions for coefficient of friction with sliding velocity for different (a) normal loads, (b) sliding distances and (c) filler percentage. (d) Coefficient of friction with respect to filler content at different normal loads. Coefficient of friction with respect to sliding distance at different (e) normal loads and (f) filler contents. 


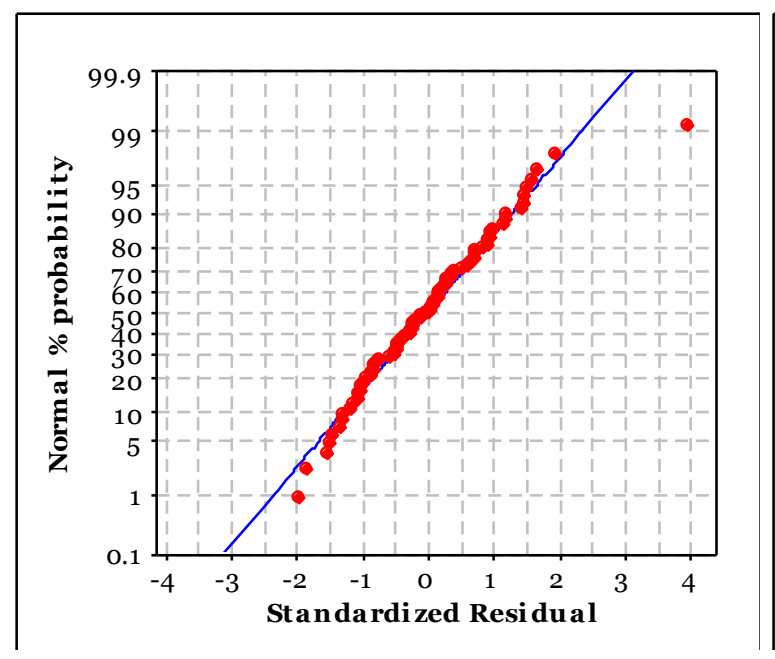

(a)

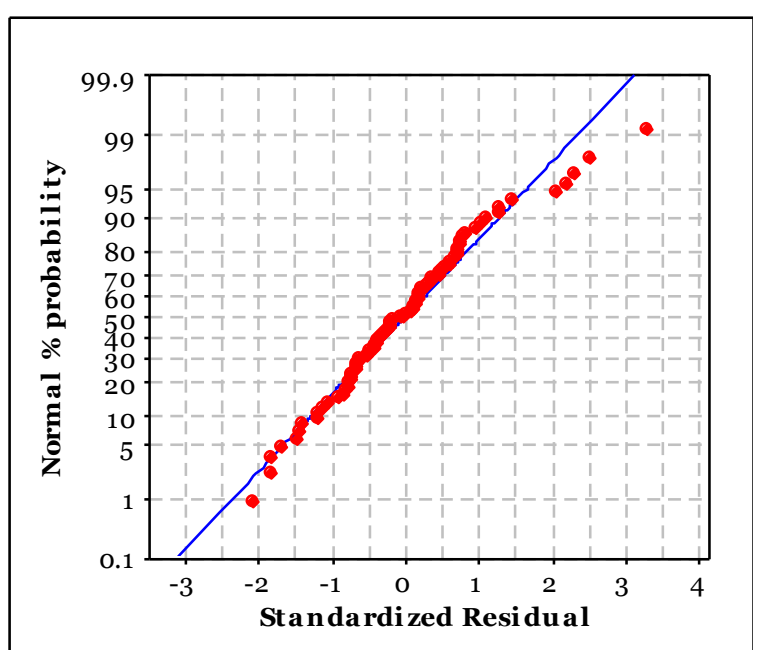

(b)

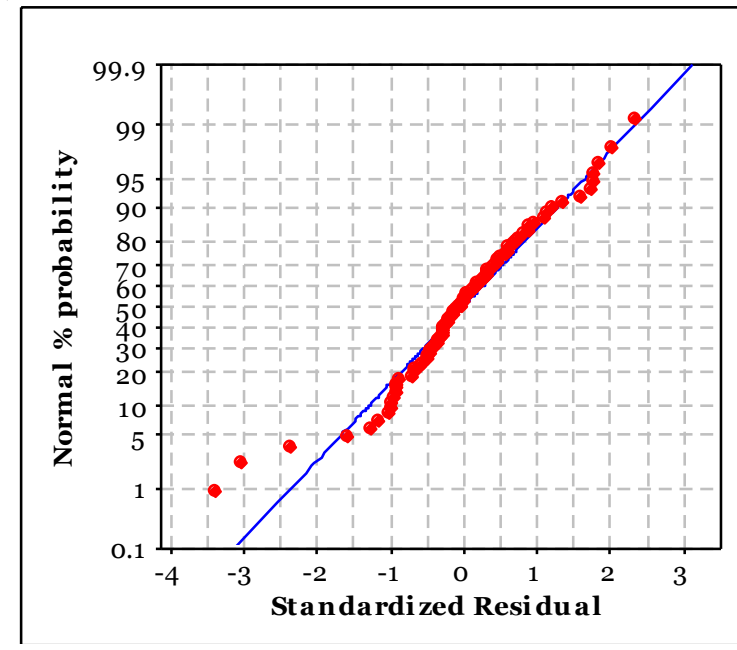

(c)

Figure 11. Normal probability plot of residuals for (a) wear rate, (b) specific wear rate and (c) coefficient of friction. 


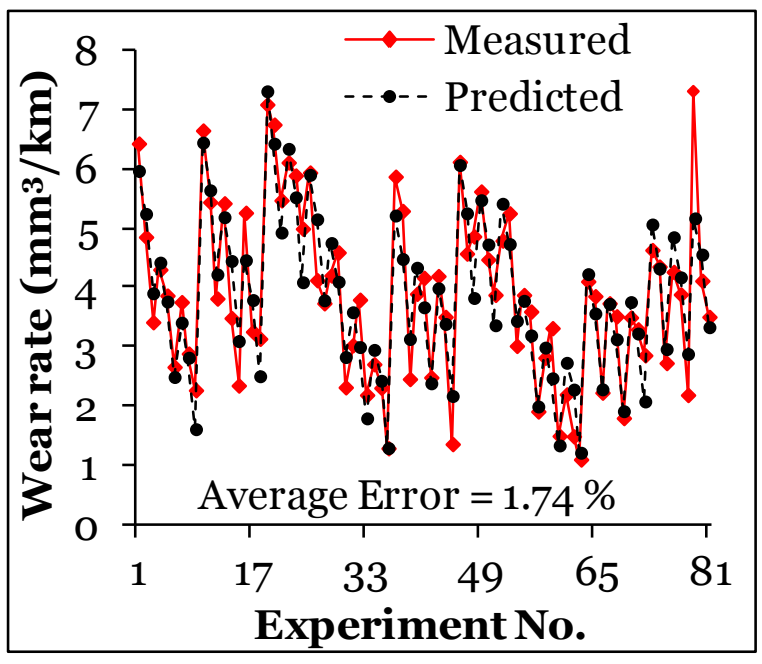

(a)

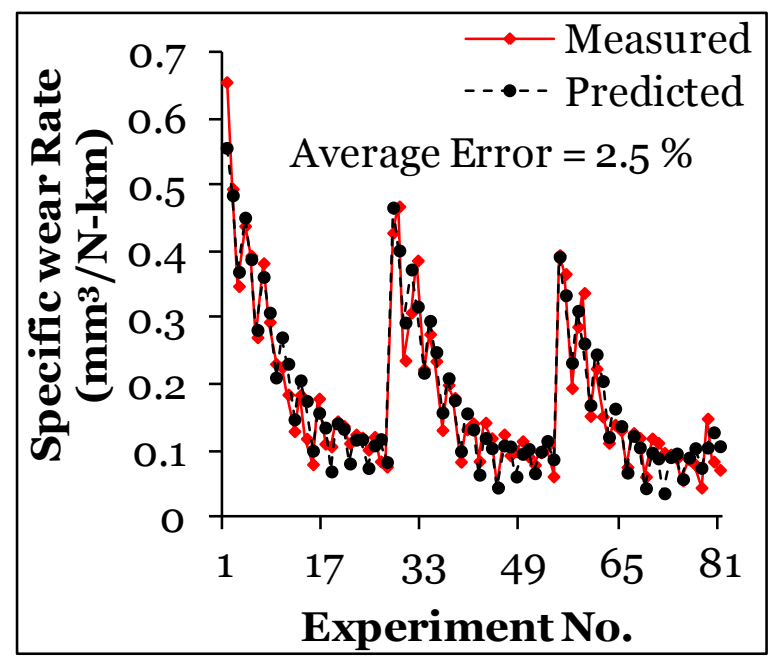

(b)

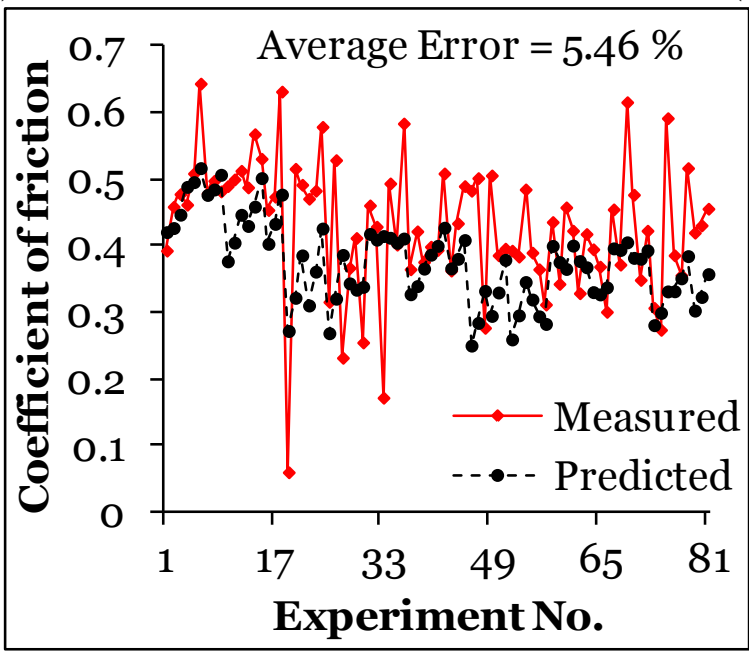

(c)

Figure 12. Comparison between measured and predicted values for (a) wear rate, (b) specific wear rate and (c) coefficient of friction. 


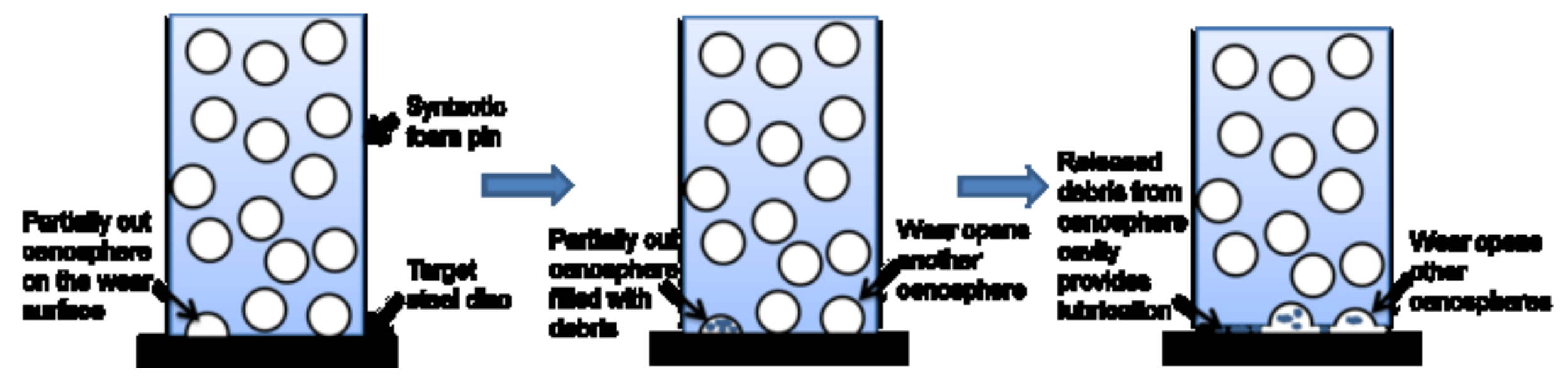

